\title{
Accessory corpus luteum induced by human chorionic gonadotropin on day 7 or days 7 and 13 of the estrous cycle affected follicular and luteal dynamics and luteolysis in lactating Holstein cows
}

\author{
Thiago O. Cunha, ${ }^{1,2}$ Leah R. Statz, ${ }^{1}$ Rafael R. Domingues, ${ }^{2}$ João Paulo N. Andrade, ${ }^{2}$ Milo C. Wiltbank, ${ }^{2}$ \\ and João Paulo N. Martins ${ }^{1 *}$ \\ ${ }^{1}$ Department of Medical Sciences, School of Veterinary Medicine, University of Wisconsin-Madison, Madison 53706 \\ ${ }^{2}$ Department of Animal and Dairy Sciences, University of Wisconsin-Madison, Madison 53706
}

\begin{abstract}
Our objective was to determine the effect of inducing an accessory corpus luteum (CL) with human chorionic gonadotropin (hCG; 3,300 IU) on d 7 (hCG7) or 2 accessory CL with hCG on d 7 and $13(\mathrm{hCG} 7+13)$ of the estrous cycle in noninseminated lactating Holstein cows. Cows $(\mathrm{n}=86)$ between 39 and 64 DIM were pretreated with an Ovsynch + CIDR protocol, and only synchronized cows were used $(\mathrm{n}=64)$. The day of the last GnRH of Ovsynch was considered d 0 of the estrous cycle. Follicular and luteal dynamics of cows were evaluated daily during an entire estrous cycle by ovarian ultrasonography. Blood samples were collected daily to measure serum concentration of progesterone $(\mathrm{P} 4)$. Cows were randomly assigned to $\mathrm{CON}(\mathrm{n}=22$, no treatment), hCG7 $(\mathrm{n}=20)$, or $\mathrm{hCG} 7+13(\mathrm{n}=22)$ treatments. Two cows from hCG7+13 failed to ovulate after hCG and were removed from the analyses posthCG treatment. The first day of luteolysis was considered the day that $\mathrm{P} 4$ declined to more than $2 \mathrm{SD}$ of the mean for the 4 consecutive $\mathrm{P} 4$ concentrations with the greatest mean in late diestrus for each individual cow. The P4 cut-off for complete luteolysis was $<1.0 \mathrm{ng} /$ $\mathrm{mL}$. Mean P4 on d $7(3.23 \pm 0.16 \mathrm{ng} / \mathrm{mL})$ did not differ among treatments. Cows treated with hCG had greater total luteal and original CL volume and serum P4 during diestrus than CON. Cows treated with hCG7+13 had greater serum P4 after d 13 of the cycle than hCG7. Cycles were classified as having atypical cycles if the dominant follicle or future dominant follicle at the time of luteolysis did not ovulate (delayed ovulation; CON, $\mathrm{n}=2$; hCG7, $\mathrm{n}=4$; hCG7+13, $\mathrm{n}=3)$, had a short cycle $(\mathrm{CON}, \mathrm{n}=1)$, delayed $(\mathrm{CON}, \mathrm{n}=2)$ or incomplete luteolysis (CON, $\mathrm{n}=1$; hCG7, $\mathrm{n}=4$; hCG7+13, $\mathrm{n}=5$ ). The remainder of cycles with normal complete
\end{abstract}

Received April 16, 2021.

Accepted November 5, 2021.

*Corresponding author: jp.martins@wisc.edu luteolysis followed by ovulation were considered to be typical. Based on blood perfusion, the CON cow with incomplete luteolysis had 2 original CL remaining functional after first onset of luteolysis. The rest of the cows with incomplete luteolysis $(9 / 10)$ had one or more CL regressing and at least one remaining functional after first onset of luteolysis. No specific pattern for CL side (ipsilateral vs. contralateral to a CL with complete regression) was observed for nonregressed CL. Cows with incomplete luteolysis had a second onset of luteolysis to undergo complete functional luteolysis. The proportion of cows with typical cycle was $73 \%(16 / 22)$ for CON, $60 \%(12 / 20)$ for hCG7, and $55 \%(11 / 20)$ for hCG7+13. Cows with typical cycles treated with hCG (hCG7 and hCG7+13) had a later onset of luteolysis, prolonged time to undergo complete luteolysis, and greater proportion of cows with 3 follicular waves than $\mathrm{CON}$, resulting in a longer interovulatory interval for hCG7 and hCG7+13 than CON. In summary, accessory CL induced by hCG during diestrus not only altered follicular and luteal dynamics but also deferred and prolonged the luteolytic process.

Key words: hCG, corpus luteum, luteolysis, dairy cows

\section{INTRODUCTION}

Over the last 4 decades, a better understanding of reproductive physiology in the modern, high-producing dairy cow provided the basis for developing novel technologies and strategies that overcome challenges to reproductive performance on dairy farms (Thatcher, 2017; Cardoso Consentini et al., 2021). An example of these technologies widely adopted in US dairy farms is Ovsynch-based fertility programs for first service of lactating dairy cows, such as Double-Ovsynch (Wiltbank and Pursley, 2014; Carvalho et al., 2018; Martins and Pursley, 2016). Many studies have been performed to improve the original Ovsynch program and maximize fertility of lactating dairy cows receiving timed-AI 
(Vasconcelos et al., 1999; Bisinotto et al., 2013; Wiltbank et al., 2015). One result that is consistent among studies is the positive association between circulating concentration of progesterone $(\mathbf{P} 4)$ during the growth of the ovulatory follicle and pregnancy per AI (Fonseca et al., 1983; Martins et al., 2011; Bisinotto et al., 2015). Fertility programs generally use a GnRH-induced LH surge to control the onset of a new follicular wave and to cause ovulation and formation of an accessory corpus luteum (CL) to enhance circulating concentration of $\mathrm{P} 4$ during the growth of the pre-ovulatory follicle (Pursley and Martins, 2011; Wiltbank and Pursley, 2014; Carvalho et al., 2018). The effects of the formation of an accessory CL and increased circulating concentration of $\mathrm{P} 4$ in timed-AI programs have been reported (Bisinotto et al., 2015; Carvalho et al., 2018). However, the effects of inducing an accessory CL with hCG treatment during the normal estrous cycle on the dynamics of follicular and luteal development and the luteolytic process have not been well established. Understanding the physiologic changes that occur after induction of accessory CL during the estrous cycle may allow the development of new strategies to maximize the fertility of lactating dairy cows inseminated after estrus.

A common strategy to induce ovulation and formation of accessory CL in lactating dairy cows is by treatment with human chorionic gonadotropin (hCG) when a dominant follicle (DF) is present on the ovary. A recent study indicated that $\geq 2,000 \mathrm{IU}$ of $\mathrm{hCG}$ has greater ovulatory efficiency than $\mathrm{GnRH}$ (86 $\mu \mathrm{g}$ of gonadorelin) when used on $\mathrm{d} 7$ of the estrous cycle in lactating dairy cows (Cabrera et al., 2021). Cabrera et al. (2021) also determined that cows treated with 2,500 IU of hCG had a greater increase in serum $\mathrm{P} 4$ concentrations from d 7 to 14 of the estrous cycle and greater total luteal volume on $\mathrm{d} 14$. These results may be due the formation of a new accessory CL combined with a luteotropic effect of hCG on the original CL because hCG binds to $\mathrm{LH}$ receptors in the CL and potentially increases $\mathrm{P} 4$ secretory capacity of luteal cells (De Rensis et al., 2010).

Most studies that used hCG to induce ovulation and formation of an accessory CL in cattle tested the effect of hCG post-AI or before embryo transfer (ET) on fertility (Nascimento et al., 2013; Besbaci et al., 2020). Their main objective was to use hCG to increase circulating concentration of $\mathrm{P} 4$ and improve early embryo development and survival (Lonergan, 2011). The results from those studies were inconsistent, with no differences (Schmitt et al., 1996b; Niles et al., 2019) or small improvements (Nascimento et al., 2013; Zolini et al., 2019) in pregnancy per AI or ET for cows and heifers treated with hCG. We only found one study by Sianangama and Rajamahendran (1996) that character- ized follicular and luteal dynamics in nonbred lactating cows treated with hCG during the dominance period of the first follicular wave. That experiment had a small number of animals ( $\mathrm{n}=6$ /treatment), and the results suggested an effect of hCG on follicular dynamics, although not statistically significant, and no effect on luteal dynamics and estrous cycle length (Sianangama and Rajamahendran, 1996).

On the contrary, a recent study from our laboratory indicated that a single administration of $3,300 \mathrm{IU}$ of hCG from d 5 to 7 of the estrous cycle increased the estrous cycle length in noninseminated lactating Holstein and Jersey cows (Cunha et al., 2021). Moreover, hCG decreased the proportion of multiparous cows returning to estrus (Cunha et al., 2021), indicating that accessory CL induced by hCG may affect luteal and luteolytic dynamics. The study did not collect ovarian and hormone data throughout the estrous cycle; therefore, it is still unclear how hCG prolonged the length of the estrous cycle. We speculated that this could be due to an increased incidence of cows with 3 follicular waves or a prolonged CL lifespan.

Hence, the objective of the present experiment was to characterize follicle and luteal dynamics and luteolysis in noninseminated lactating Holstein cows that form accessory CL due to treatment with hCG either on d 7 only or on both d 7 and 13 of the estrous cycle. Our first hypothesis was that hCG treatment on $\mathrm{d} 7$ would increase the proportion of cows with 3 follicular waves compared with cows that did not receive any treatment (controls). Our second hypothesis was that cows with accessory CL induced by hCG would have a prolonged interovulatory interval (IOI). Our final hypothesis was that cows treated with hCG on d 7 and 13 would have follicles from the third wave growing in such synchrony that there would be a decrease in variation for the onset of functional luteolysis, synchronizing the time of luteolysis.

\section{MATERIALS AND METHODS}

All procedures involving animals were previously approved by the Institutional Animal Care and Use Committee (IACUC) of the University of WisconsinMadison (Protocol ID: A006164). No humane endpoints were observed during the study.

\section{Animals, Housing, and Feeding}

From May to September 2019, a total of 86 lactating Holstein cows from 2 research farms in south central Wisconsin were enrolled in this study. Cows were housed in freestall barns and milked twice daily at the Emmons Blaine Dairy Cattle Center $(\mathrm{n}=23$; Arling- 


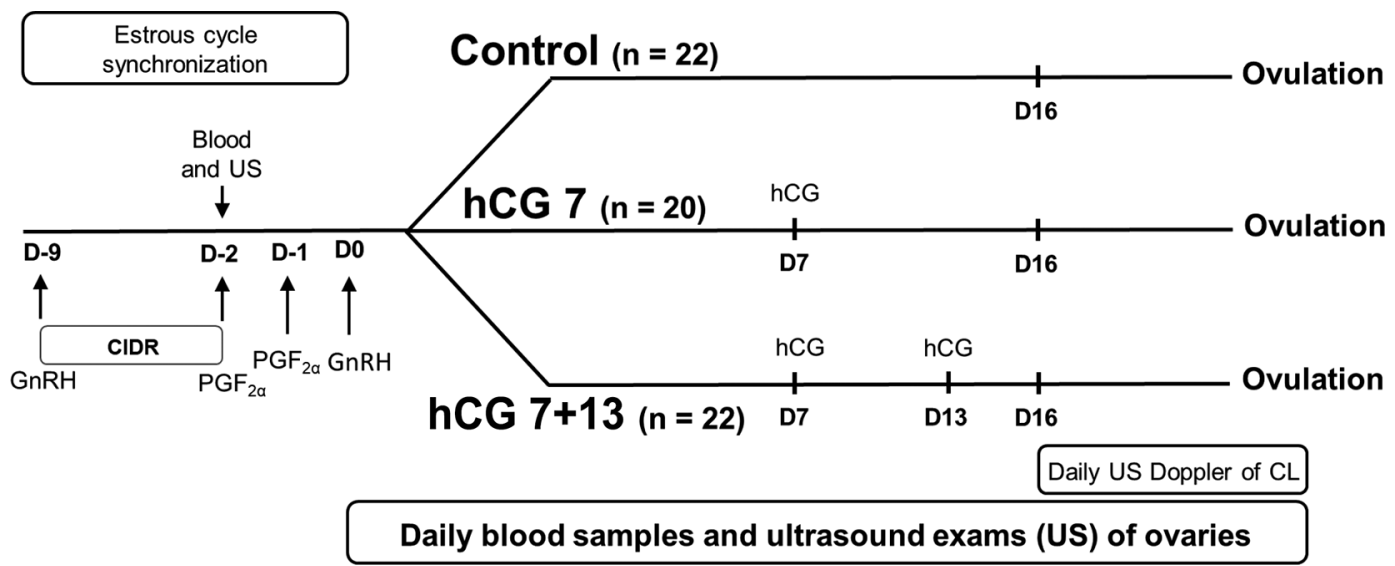

Figure 1. Schematic diagram of the experimental design. The estrous cycle of lactating Holstein cows was synchronized with an Ovsynch + controlled internal drug-release insert (CIDR) protocol [GnRH $200 \mu \mathrm{g}$ and CIDR insertion on d -9 ; CIDR removal and 25 mg of PGF $2 \alpha$ (dinoprost tromethamine) on $\mathrm{d}-2 ; \mathrm{PGF}_{2 \alpha}$ on $\mathrm{d}-1$; GnRH $200 \mu \mathrm{g}$ on d 0]. After confirmation of ovulation by the last GnRH (d 0), cows were randomly assigned to each treatment. Cows in the control treatment did not receive any treatment. Cows in the hCG7 treatment received 3,300 IU of human chorionic gonadotropin (hCG) $7 \mathrm{~d}$ after the last $\mathrm{GnRH}$ (d 7 of the estrous cycle). Cows in the hCG7+13 treatment received 3.300 IU of hCG on d 7 and a second treatment with hCG on d 13 of the estrous cycle. Transrectal ultrasonography (US) and blood collection were performed on d -2 and daily from d 0 until spontaneous ovulation. After d 16 of the estrous cycle, Doppler US was performed in each corpus luteum (CL) until at least 2 consecutive days with blood flow $\leq 25 \%$ in all CL of each cow.

ton, WI). At the US Dairy Forage Research Center $(\mathrm{n}=63$; Prairie du Sac, WI $)$, cows were housed in tiestall barns and milked thrice daily. On both farms, cows had free access to water and fresh TMR delivered once daily, which consisted of corn and alfalfa silage as forage and corn-soybean meal-based concentrate. Individual milk yield from cows was measured daily, and BCS (scale from $1=$ thin to $5=$ fat; Edmonson et al., 1989) was evaluated on the day of enrollment. The daily average temperature-humidity index (THI; NRC, 1971) during the experimental period from the nearest meteorological station to both farms (Dane County Regional Airport, Madison, WI) was $63.5 \pm 3.1( \pm \mathrm{SD})$, calculated as follows: $\mathrm{THI}=(1.8 \times$ temperature dry bulb +32$)-[(0.55-0.0055 \times$ relative humidity $) \times$ $(1.8 \times$ temperature dry bulb -26.8$)]$.

\section{Experimental Design and Selection of Animals}

Cows between 39 and 64 DIM (mean $\pm \mathrm{SD}=45.2 \pm$ 6.0) were submitted to a pretreatment for synchronization of ovulation, consisting of an Ovsynch + controlled internal drug-release insert (CIDR; Figure 1; Pursley et al., 1995). Briefly, cows received GnRH (200 $\mu$ g i.m.; Factrel, Zoetis) and a P4 intravaginal insert (EaziBreed CIDR; Zoetis). Seven days later, the P4 insert was removed, and prostaglandin $\mathrm{F}_{2 \alpha}\left(\mathrm{PGF}_{2 \alpha} 25 \mathrm{mg}\right.$ i.m.; Lutalyse HighCon, Zoetis) was administered, followed by another $\mathrm{PGF}_{2 \alpha} 1 \mathrm{~d}$ later and a second $\mathrm{GnRH}$ $1 \mathrm{~d}$ after the second $\mathrm{PGF}_{2 \alpha}$. Only synchronized cows with complete CL regression $2 \mathrm{~d}$ after $\mathrm{PGF}_{2 \alpha}$ (serum $\mathrm{P} 4$ $<1.0 \mathrm{ng} / \mathrm{mL}$ ) and ovulation by $2 \mathrm{~d}$ after the last $\mathrm{GnRH}$ were used in the study $(\mathrm{n}=64)$. The last $\mathrm{GnRH}$ of pretreatment was considered d 0 of the estrous cycle. After confirmation of synchronization, cows were randomly assigned to one of 3 treatments. Control cows $(n=22)$ did not receive any treatment except the synchronization protocol. Cows enrolled in the second treatment group (hCG $\mathbf{h} ; \mathrm{n}=20$ ) received an i.m. treatment with 3,300 IU of hCG (Chorulon, Merck Animal Health) 7 d after the last GnRH (d 7 of the cycle), and cows enrolled in the third treatment group $(\mathbf{h C G} \mathbf{7}+\mathbf{1 3} ; \mathrm{n}=$ 22 ) received $2 \mathrm{hCG}$ treatments with $3,300 \mathrm{IU}$, one on d 7 and a second on d 13 after the last GnRH (d 7 and d 13 of the estrous cycle).

\section{Ultrasonography}

A technician blinded to treatments scanned and mapped ovaries using a transrectal ultrasonography fitted with a 5 to $10 \mathrm{MHz}$ multifrequency linear array probe (SonoSite Edge, Fujifilm SonoSite Inc.) on the day of the first $\mathrm{PGF}_{2 \alpha}$ treatment of pretreatment (d -2) and daily from the day of GnRH (d 0) until the end of the cycle determined by spontaneous ovulation. Ovarian ultrasonographic videos of each cow were recorded and used for later measurement of follicular and luteal structures using a video analysis software for measurements (Kinovea version 0.9.1, https://kinovea .org). Measurements were performed by a technician blinded to treatments. The $10-\mathrm{mm}$ distance between grid-scale on the ultrasound display was used to calibrate the measuring calipers of the software. The height and width of the largest cross-sectional size of 
follicles with an antrum diameter $\geq 4 \mathrm{~mm}$ and any detectable CL were measured. Corpus luteum volume was calculated by the formula $\mathrm{V}=4 / 3 \times \pi \times \mathrm{R}^{3}$ using a radius $(\mathbf{R})$ calculated by the formula $R=$ (Height $/ 2$ + Width/2)/2. Corpora lutea with fluid-filled central cavity also had the largest cross-sectional area of the cavity measured and subtracted from the total volume of the CL. Ovulation was characterized by the disappearance of the DF or co-dominant follicles, followed by the detection of a newly formed CL at the same location. Starting on d 16 of the estrous cycle, all cows had every CL present in the ovaries scanned daily using a color Doppler function to determine CL blood flow. Based on colored pixel intensity indicating blood flow, a subjective scale through vascularization scores $(0=$ no blood flow and $4=$ maximum blood flow) based on Pugliesi et al. (2017) was used to evaluate the functionality of each CL. Doppler evaluations ended after at least 2 consecutive days with blood flow $\leq 25 \%$ for all CL present in the ovaries.

\section{Blood Sampling and P4 Assays}

Blood samples were collected immediately before the first $\mathrm{PGF}_{2 \alpha}$ treatment and $\mathrm{CIDR}$ removal $(\mathrm{d}-2)$ and daily from d 0 until spontaneous ovulation. Samples were collected via coccygeal venipuncture into $10-\mathrm{mL}$ evacuated serum collection tubes (Vacuette, Greiner Bio-One North America Inc.). After collection, blood samples were placed in a cooler with ice and transported to the laboratory. Samples were centrifuged (20 min at 2,000 $\mathrm{x} g ; 4^{\circ} \mathrm{C}$ ) within $6 \mathrm{~h}$, and serum aliquots were separated and frozen at $-20^{\circ} \mathrm{C}$ until assayed. Progesterone concentrations were analyzed in serum by radioimmunoassay using a commercial kit (MP Biomedicals). Ten assays were performed and the sensitivity values of the assays were $\leq 0.05 \mathrm{ng} / \mathrm{mL}$. All samples from the same cow were analyzed within the same assay, and cows from each week of enrollment and treatment were randomized for all assay rounds. Samples with P4 concentration $=2.0 \mathrm{ng} / \mathrm{mL}$ were incorporated in duplicates at the beginning, middle, and end of each assay for quality control and calculation of intra- and interassay coefficients of variation. Intra- and interassay coefficients of variation were 8.1 and $10.4 \%$, respectively.

\section{Definition of Luteolysis and Classification of Atypical Estrous Cycle}

The first day of functional luteolysis was considered the day $\mathrm{P} 4$ declined by twice the SD of the mean for the 4 consecutive days serum $\mathrm{P} 4$ concentrations with the greatest mean in the late diestrus. The day of luteolysis onset was considered the day before the first day of functional luteolysis. The circulating P4 concentration cut-off for complete functional luteolysis was $<1.0 \mathrm{ng} /$ $\mathrm{mL}$.

Cows were categorized as having either a typical or an atypical estrous cycle. Cycles were classified as atypical with delayed ovulation if the DF or the future $\mathrm{DF}$ at the onset of luteolysis was not the ovulatory follicle (Sartori et al., 2004). Cows that had an early luteolysis or short cycle $(\leq 16 \mathrm{~d})$, delayed luteolysis onset ( $>$ d 23 of the cycle), or incomplete functional luteolysis (did not complete CL regression by $6 \mathrm{~d}$ after the onset of luteolysis) were also considered to have an atypical cycle. The remainder of cycles with onset of luteolysis $\leq 23 \mathrm{~d}$ of the cycle followed by complete luteolysis within $6 \mathrm{~d}$ after the onset and ovulation of the DF or future DF at the onset of luteolysis were considered typical. The effect of treatment on follicular and luteal dynamics after $\mathrm{d} 13$ of the estrous cycle was analyzed separately for cows with typical and atypical cycles, aiming to eliminate misleading effects of atypical estrous cycle (delayed ovulation, and early, incomplete and delayed luteolysis) on the results. For cows classified with incomplete luteolysis, the day of second onset of luteolysis was based on the same criteria used for the first day of functional luteolysis.

\section{Statistical Analysis}

The total number of cows needed in this experiment was calculated using $\mathrm{G}^{*}$ Power (Faul et al., 2007). A priori power analysis using the $\mathrm{z}$ test to calculate a difference between 2 independent proportions, 2-tailed, $\alpha=0.05$, power $(1-\beta)=0.95$, indicated that 10 cows per treatment were required to detected a difference between 20 versus $90 \%$ in the proportion of cows with 3 follicular waves in the estrous cycle for control versus hCG7 or hCG7+13, respectively. We doubled the number of cows per treatment in the study to account for a large proportion of cows with atypical cycles in spontaneous estrous cycles $(\sim 50 \%)$ previously identified by Sartori et al. (2004).

This study used a complete randomized experimental design. Cows were randomly assigned to treatments after confirmation of ovulation by ultrasonography to the last GnRH of the pretreatment protocol. Cows that failed to ovulate to the $\mathrm{d} 7$ or d $13 \mathrm{hCG}(\mathrm{hCG} 7+13$, n $=2$ ) were removed from the statistical analysis for variables analyzed after each hCG treatment. All statistical analyses in this study were performed using SAS (version 9.4, SAS Institute Inc.).

Continuous data related to follicular dynamics, milk production, BCS were tested for differences by ANOVA, and differences among treatments and for typical versus atypical cycles were obtained by differences of least 
squares means using the linear mixed model applying the MIXED procedure of SAS. The model considered the effect of parity and treatment as fixed effects. Parity was only maintained in the model when provided a lower value of the Akaike information criterion (AIC). Normality and homoscedasticity of residuals were assessed by visual inspection of studentized residual plots for each variable after fitting the model using the residual option of the MIXED procedure. When necessary, the assumption of normality was tested using the Shapiro-Wilk test within the UNIVARIATE procedure of SAS. Variables that did not fulfill assumptions were natural log-transformed for the analysis and actual means \pm standard error of the mean of the data are presented for clarity. Means and SEM were obtained using the MEANS procedure.

Because the onset of functional luteolysis occurred on different days of the cycle among most cows and treatments, data at the end of the luteal phase relating to luteal dynamics were normalized for days relative to the onset of functional luteolysis ( $\mathrm{d}-5$ to 5 ).

Repeated measures variables such as the mean P4 concentration and CL volume over time (estrous cycle day or day relative to the onset of luteolysis) were analyzed using the MIXED procedure with the REPEATED statement with cow specified in the SUBJECT option of SAS. The model consisted of parity, treatment, time and the interaction treatment $x$ time as fixed effects. Parity was only maintained in the model when provided a lower value of the AIC. For the MIXED procedure, fit statistic parameters for unstructured, compound symmetry, first-order autoregression, heterogeneous compound symmetry, and heterogeneous first-order autoregression variance structure were tested. The covariance structure with the lowest values for AIC was used for the analysis. The analysis was divided into 3 time periods based on the expected estrous cycle status in each phase, allowing comparisons between treatments with less variability of the residuals that could lead to distorted interpretations. The 3 phases for serum $\mathrm{P} 4$ and total luteal and CL volumes analysis are as follows: $\mathrm{d}-2$ to 7 (pretreatment phase), d 7 to 14 (posttreatment phase before natural luteolysis), and d -5 to 5 relative to the onset of functional luteolysis.

Binary data such as double ovulation to d $0 \mathrm{GnRH}$ and $\mathrm{d} 7 \mathrm{hCG}$, and the proportion of cows with typical estrous cycle, 3 follicular waves, and spontaneous double ovulation were analyzed by Fisher's exact test with the FREQ procedure. We used Fisher's exact test because the outcome with counts fewer than 5 was present in at least one of the treatment results from the variables listed.
Levene's test was used to assess if treatments had different variability for days at the onset of luteolysis. The GLM procedure with HOVTEST option in the MEANS statement was applied. If variances differed, the Welch's $t$-test within the GLM procedure was used for pairwise comparisons of 2 means.

All analyses used a 2-tailed test. Probability values were considered different when $P$-values were $\leq 0.05$, and trending toward significance when $P$-values were $>0.05$ and $\leq 0.10$.

\section{RESULTS}

Average lactation number, BCS at enrollment, and milk production during the trial did not differ among treatments $(P=0.34 ; P=0.58 ; P=0.91$; respectively). Overall mean lactation number and BCS were $2.3 \pm 0.03$ and $3.1 \pm 0.04$, respectively. The overall mean daily milk production was $36.8 \pm 0.9 \mathrm{~kg}$ for primiparous and $50.4 \pm 1.0 \mathrm{~kg}$ for multiparous cows during the experiment. By the time of the first $\mathrm{PGF}_{2 \alpha}$ of pre-treatment, all cows enrolled in the study had at least one CL present in one of the ovaries, and serum $\mathrm{P} 4$ was similar $(P=0.26)$ among treatments averaging $5.3 \pm 0.4 \mathrm{ng} / \mathrm{mL}$. Largest follicle diameter at the final $\mathrm{GnRH}$ of the pretreatment (d 0) averaged $15.0 \pm 0.4$ $\mathrm{mm}$ and did not differ among treatments (Table 1). No treatment differences were found for day of first follicular wave emergence $(1.4 \pm 0.1 \mathrm{~d})$ and first-wave DF diameter at d $7(13.1 \pm 0.3 \mathrm{~mm}$; Table 1$)$.

\section{Effect of Treatment on Follicular Dynamics}

Treatment affected day of second follicular wave emergence (Table 1). As expected, the average day of second follicular wave emergence for cows that ovulated to the first hCG (hCG7 and hCG7+13) was earlier $(P$ $<0.001)$ compared with the cows in the control group $(8.8 \pm 0.1$ vs. $d 12.1 \pm 0.6$, respectively). Although a greater proportion of cows had double ovulation to hCG treatment on d 7 in hCG7+13 compared with hCG7, the DF diameter at d 13 did not differ for cows in hCG7 versus hCG7+13 (Table 1). Moreover, DF diameter at d 13 did not differ $(P=0.18)$ for cows with double ovulation and single ovulation to d 7 hCG (10.9 \pm 0.4 vs. $10.1 \pm 0.5$, respectively). Most cows with double ovulations to d 7 or 13 hCG were multiparous $(14 / 17)$ and occurred by random chance. Interestingly, $3 / 4$ of the cows with double ovulation to d $13 \mathrm{hCG}$ also double ovulated to d 7 hCG.

Thirty-nine of 62 cows in this study were characterized as having typical cycles (Table 2). Supplemental Figure S1 (http://digital.library.wisc.edu/1793/82420; 
Table 1. Effect of treatment (control, hCG7, and hCG7+13) on follicular dynamics of first and second follicular wave in lactating Holstein cows

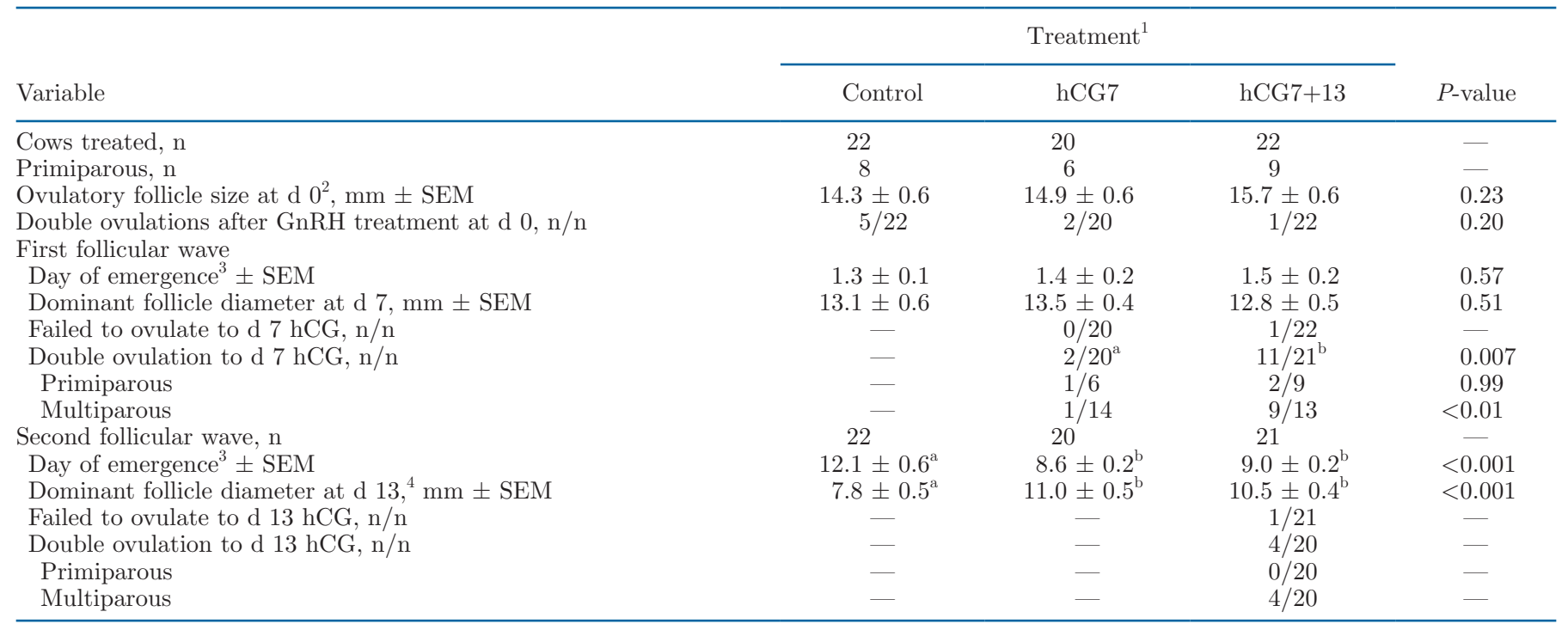

\footnotetext{
$\overline{\mathrm{a}, \mathrm{b}}$ Mean values in the same row with different superscripts differ $(P \leq 0.05)$. ment with hCG on d 13 of the estrous cycle.

${ }^{2} \mathrm{~d} 0=$ day of last $\mathrm{GnRH}$ treatment.

${ }^{3}$ Day of emergence was the day that follicles with a diameter of $\geq 4 \mathrm{~mm}$ were detected by ultrasound.

${ }^{4}$ Only $\mathrm{n}=13$ cows were considered for the control at $\mathrm{d} 13$ of the estrous cycle.
}

${ }^{1}$ Cows in the control treatment did not receive any treatment. Cows in the hCG7 treatment received 3,300 IU of human chorionic gonadotropin (hCG) $7 \mathrm{~d}$ after the last GnRH (d 7 of the estrous cycle). Cows in the hCG7+13 treatment received 3,300 IU of hCG on d 7 and a second treat-

Martins, 2021) has examples of individual cows for serum concentration of P4, luteal volume, and CL Doppler scores for cows in each treatment classified with typical estrous cycles. Treatment did not affect the proportion of cows with typical cycles but increased the proportion of cows with 3 follicular waves compared with control cows (Table 2). Day of the emergence of the pre-ovulatory follicular wave was later for cows treated with hCG (hCG7 or hCG7+13) compared with controls (Table 2). Furthermore, pre-ovulatory follicle diameter at the onset of functional luteolysis was smaller for cows treated with hCG than controls (Table 2). Nevertheless, the age and maximum diameter of the pre-ovulatory follicle in the final wave did not differ among treatments (Table 2). Cows treated with hCG (hCG7 or hCG7+13) had a prolonged period between onset of functional luteolysis and ovulation and had a longer IOI (Table 2).

\section{Effect of Treatment on Luteal Dynamics and Luteolysis}

Circulating P4 concentration and luteal volume did not differ among treatments until d 7 of the estrous cycle (Figure 2). On average, cows in hCG7 or hCG7+13 had a greater number of CL (CL number on day of luteolysis: Control $=1.2 \pm 0.1 ;$ hCG7 $=2.3 \pm 0.1 ;$ hCG7 +13 $=3.5 \pm 0.2 P<0.001)$, circulating concentrations of
P4 (Figure 2A), and total luteal volume (Figure 2B) during diestrus (d 9 to 13) than control cows (Table 3). In contrast, no differences in serum $\mathrm{P} 4$ and luteal volume were observed between hCG treatments (hCG7 vs. hCG7+13) within the same period (Figure 2), even with a greater proportion of cows with double ovulation following $\mathrm{hCG}$ administration on $\mathrm{d} 7$ in the $\mathrm{hCG} 7+13$ treatment compared with hCG7 treatment (Table 1). Human chorionic gonadotropin treatment on $\mathrm{d} 7$ of the estrous cycle enhanced growth of the original CL from d 7 to 9 compared with control cows, resulting in greater $(P<0.01)$ original CL volume for hCG7 and hCG7+13 cows between d 10 and 13 than controls (Figure 2C). Control cows maintained $(P>0.10)$ similar original CL volume between d 8 and 14 of the estrous cycle and between $\mathrm{d}-5$ and 0 relative to the onset of functional luteolysis (Figure 2). In contrast, the original CL volume in hCG7 and hCG7+13 decreased on some days $(P<$ 0.05 ) between $\mathrm{d}-5$ and 0 relative to luteolysis (Figure $2 \mathrm{C})$. However, the second hCG on d 13 of the estrous cycle in the hCG7+13 maintained a larger original CL volume for an extended period during the estrous cycle than hCG7 (Figure 2C). From d -5 to d 0 relative to the onset of luteolysis, circulating concentrations of P4 and luteal volume were different among treatments, except at $\mathrm{d}-5$ when luteal volume only had a tendency $(P=0.07)$ to be different between hCG7 and hCG7+13 (Figure 2B). 
Table 2. Effect of treatment (control, hCG7, and hCG7+13) on the proportion of cows with typical estrous cycle, 2 or 3 follicular waves, follicular dynamics of the pre-ovulatory follicle, day of spontaneous ovulation and interovulatory interval in lactating Holstein cows

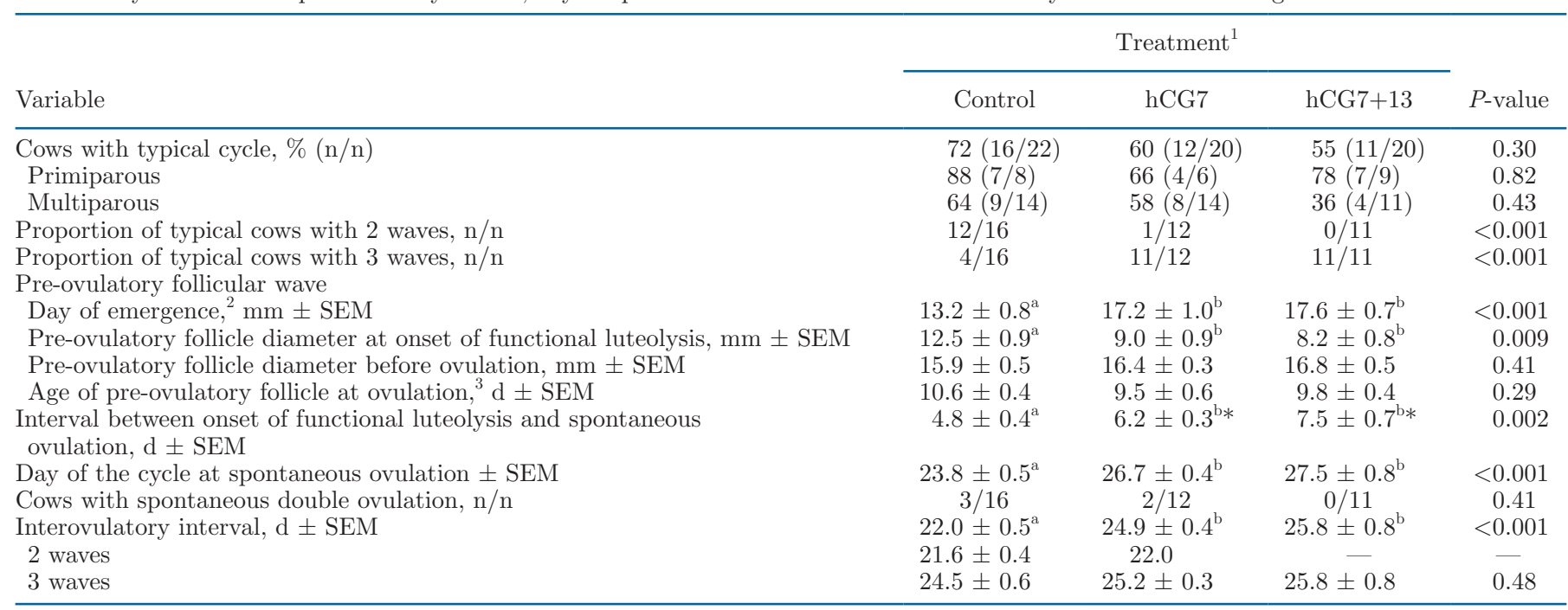

${ }_{\mathrm{a}, \mathrm{b}}$ Mean values in the same row with different superscripts differ $(P \leq 0.05)$.

${ }^{1}$ Cows in the control treatment did not receive any treatment. Cows in the hCG7 treatment received 3,300 IU of human chorionic gonadotropin (hCG) $7 \mathrm{~d}$ after the last $\mathrm{GnRH}$ (d 7 of the estrous cycle). Cows in the hCG7+13 treatment received 3,300 IU of hCG on d 7 and a second treatment with hCG on d 13 of the estrous cycle.

${ }^{2}$ Day of emergence was the day that follicles with a diameter of $\geq 4 \mathrm{~mm}$ were detected by ultrasound.

${ }^{3}$ Interval between the day of emergence and the day before ovulation.

*Mean values in the same row with asterisks tended to differ $(0.05<P \leq 0.10)$.

Cows treated with hCG had later onset of functional luteolysis during the estrous cycle (Table 4). However, the day of the cycle at the onset of functional luteolysis did not differ between control cows with 3 follicular waves and cows receiving hCG treatments that also had 3 follicular waves (Table 4). Cows with accessory CL also had a prolonged period between the onset of functional luteolysis and time to complete luteolysis (serum P4 $<1 \mathrm{ng} / \mathrm{mL}$; Figure 3A; Table 4). Interaction treatment by day relative to functional luteolysis was observed on accessory CL volume during luteolysis, indicating that the rate of accessory CL volume reduction after the onset of luteolysis differed among treatments (Figure 3C). Treatment with hCG and/or accessory CL presence had an effect not only on the timing of functional luteolysis but also on structural luteolysis timing. Although the period between the onset of functional luteolysis and $\mathrm{P} 4<1 \mathrm{ng} / \mathrm{mL}$ was shorter for cows in control with 3 follicular waves than hCG treatments, the interval between onset of functional luteolysis and ovulation was similar for cows with 3 follicular waves between treatments (Table 4). Furthermore, the IOI did not differ between treatments in cows with 3 follicular waves (Table 1).

When cows with typical and atypical estrous cycle were combined within each treatment, hCG treatments reduced the variation in timing of the onset of luteolysis among cows in hCG7 or hCG7+13 compared with
CON (Figure 4A). Variation of day of complete luteolysis and IOI did not differ $(P>0.10)$ between treatments, as indicated in Figure 4 (B and C, respectively).

\section{Atypical Versus Typical Estrous Cycles}

Parity $(P=0.15)$, BCS $(P=0.32)$, and milk production $(P=0.15)$ did not differ between cows with typical and atypical cycles. A total of $23 / 62$ (37.1\%) cows had an atypical estrous cycle. One cow in control had an early luteolysis onset and short cycle with only one follicular wave, $13 \mathrm{~d}$ at the onset of luteolysis and an IOI of 16 d (Supplemental Figure S2; http://digital .library.wisc.edu/1793/82420; Martins, 2021). Ten cows had an atypical cycle with delayed ovulation of the DF or future DF at the time of luteolysis not subsequently ovulating (control, $\mathrm{n}=1$; hCG7, $\mathrm{n}=4$; hCG7+13, $\mathrm{n}=$ 4; Supplemental Figure S3; http://digital.library.wisc .edu/1793/82420; Martins, 2021). Regardless of treatment or parity, day of onset of luteolysis did not differ $(P=0.64)$ for cows with delayed ovulation and typical estrous cycles (Table 5; Figure 5). These cows with delayed ovulation had one $(\mathrm{n}=2 / 10)$ or $2(\mathrm{n}=8 / 10)$ additional follicular waves after the onset of luteolysis and a total of 3 to 5 waves during the estrous cycle. Due to the additional follicular wave(s), the period between the onset of luteolysis and ovulation was longer $(P<$ 0.001 ) for cows with delayed ovulation than for cows 

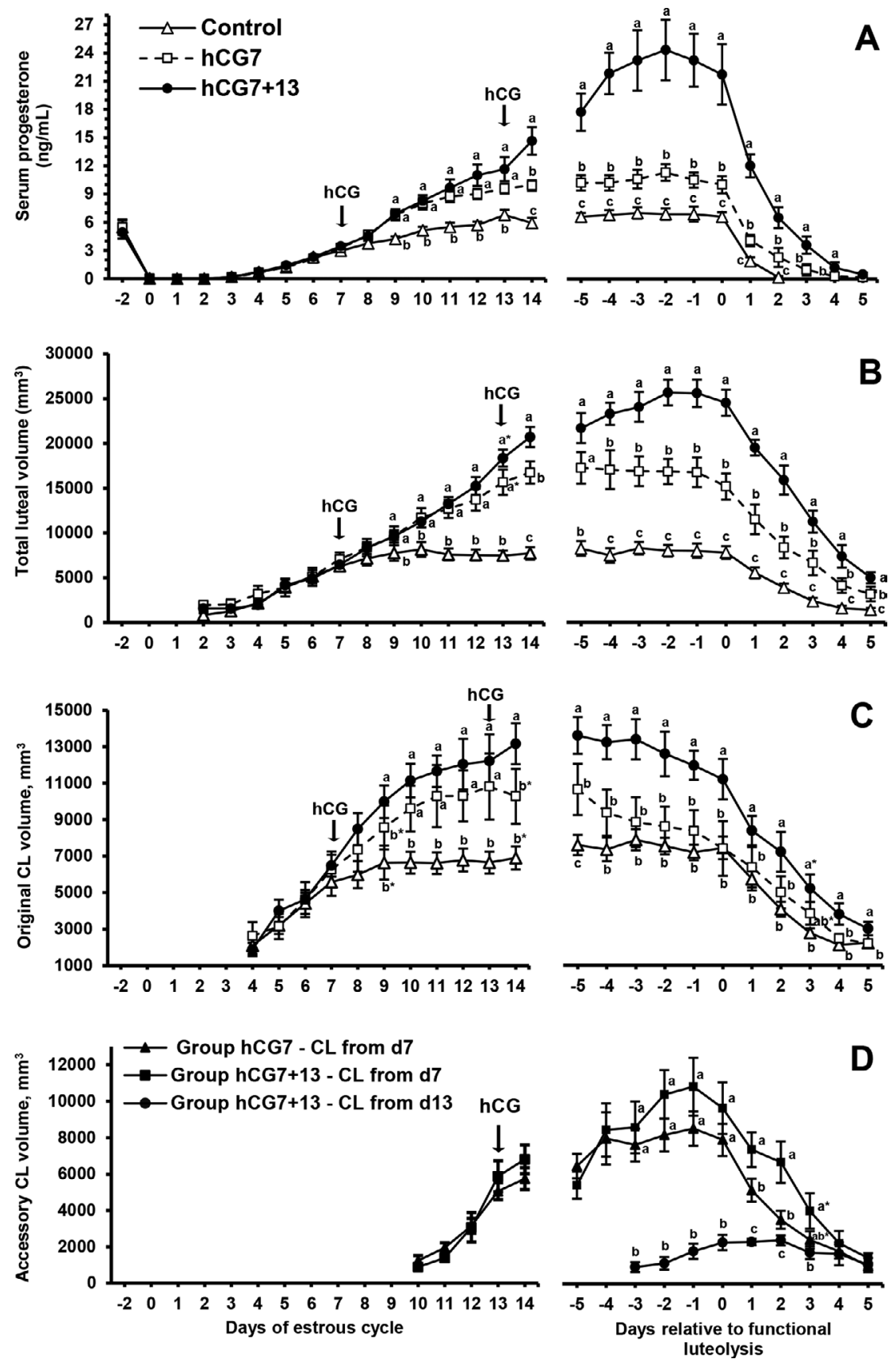

Figure 2. Effect of treatment (control, hCG7, and hCG7+13) on mean ( \pm SEM) serum progesterone (P4) concentrations (A), total luteal volume (B), original corpus luteum (CL; C), and accessories CL (D) volume during an entire estrous cycle in lactating dairy cows with typical cycle. (A; serum P4): From $d-2$ to 7 of the cycle $(\mathrm{n}=64)$ : estrous cycle day (Day): $P<0.001$; treatment $($ TRT): $P=0.73$; and Day $\times$ TRT: $P=0.22$. From d 7 to 14 of the cycle $(\mathrm{n}=62)$ : Day: $P<0.001$; TRT: $P<0.001$; and Day $\times$ TRT: $P<0.001$. From d -5 until d 5 relative to the onset of functional luteolysis $(\mathrm{n}=39$, only cows with typical estrous cycles): Day: $P<0.001$; TRT: $P<0.001$; and Day $\times$ TRT: $P<0.001$. (B; total luteal volume): From d 2 to 7 of the cycle $(\mathrm{n}=64)$ : Day: $P<0.001$; TRT: $P=0.28$; and Day $\times$ TRT: $P=0.23$. From d 7 to 14 of the cycle $(\mathrm{n}=62)$ : Day: $P<0.001$; TRT: $P<0.001$; and Day $\times$ TRT: $P<0.001$. From d -5 until $\mathrm{d} 5$ relative to the onset of functional luteolysis (n $=39$, only cows with typical estrous cycle): Day: $P<0.001$; TRT: $P<0.001$; and Day $\times$ TRT: $P<0.001$. (C; original CL volume): Only cows with typical estrous cycle and single ovulation at d 0 (Control, $\mathrm{n}=13$; hCG7, $\mathrm{n}=11$; hCG7 $+13, \mathrm{n}=10)$ were used in these analyses. From d 2 to 7: Day: $P<0.001$; TRT: $P=0.55$; and Day $\times$ TRT: $P=0.17$. From d 7 to 14 of the cycle $(\mathrm{n}=62)$ : Day: $P<0.001$; TRT: $P<$ 0.001; and Day $\times$ TRT: $P=0.54$. From d -5 until d 5 relative to the onset of functional luteolysis: Day: $P<0.01 ;$ TRT: $P<0.01$; and Day $\times$ TRT: $P=0.01$. (D; accessories CL volume): Only cows with typical estrous cycle and single ovulation at $\mathrm{d} 0(\mathrm{Control}, \mathrm{n}=13 ; \mathrm{hCG} 7, \mathrm{n}=11 ;$ $\mathrm{hCG} 7+13, \mathrm{n}=10$ ) were used in these analyses. From d 10 to 14: Day: $P<0.001$; TRT: $P=0.31$; and Day $\times$ TRT: $P=0.06$. From d -5 until d 5 relative to the onset of functional luteolysis: Day: $P<0.001$; TRT: $P<0.001$; and Day $\times$ TRT: $P<0.001$. Different letters $(\mathrm{a}-\mathrm{c})$ within a day represent differences between $\operatorname{LSM}(P \leq 0.05)$, and letters with asterisks within a day represent a tendency $(0.05<P \leq 0.10)$ for a difference. $\mathrm{hCG}=$ human chorionic gonadotropin. 
Table 3. Effect of treatment (control, hCG7, and hCG7+13) on total luteal volume, original and accessory corpus luteum (CL) volume and circulating progesterone (P4) concentrations on $\mathrm{d} 7, \mathrm{~d} 13$ and $\mathrm{d}$ of onset of functional luteolysis in lactating dairy cows classified with typical estrous cycle

\begin{tabular}{|c|c|c|c|c|}
\hline Variable & \multicolumn{3}{|c|}{ Treatment } & $P$-value \\
\hline \multicolumn{5}{|l|}{ d 7 of the estrous cycle } \\
\hline Total luteal volume, $\mathrm{mm}^{3} \pm \mathrm{SEM}$ & $6,374 \pm 758$ & $7,022 \pm 1,182$ & $7,009 \pm 669$ & 0.83 \\
\hline Serum $\mathrm{P} 4, \mathrm{ng} / \mathrm{mL} \pm \mathrm{SEM}$ & $3.2 \pm 0.3$ & $3.3 \pm 0.5$ & $3.6 \pm 0.3$ & 0.46 \\
\hline \multicolumn{5}{|l|}{ d 13 of the estrous cycle } \\
\hline 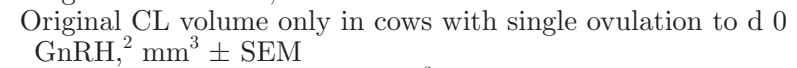 & $6,646 \pm 596^{\mathrm{a}}$ & $10,809 \pm 1,814^{\mathrm{b}}$ & $11,208 \pm 1,471^{\mathrm{b}}$ & 0.001 \\
\hline Total accessory CL volume, $\mathrm{mm}^{3} \pm \mathrm{SEM}$ & - & $4,951 \pm 399$ & $6,370 \pm 622$ & 0.20 \\
\hline Serum $\mathrm{P} 4, \mathrm{ng} / \mathrm{mL} \pm \mathrm{SEM}$ & $7.0 \pm 0.5^{\mathrm{a}}$ & $9.6 \pm 0.7^{\mathrm{b}}$ & $13.8 \pm 2.1^{\mathrm{b}}$ & $<0.001$ \\
\hline \multicolumn{5}{|l|}{ Day of onset of functional luteolysis } \\
\hline Number of CL \pm SEM & $1.2 \pm 0.1^{\mathrm{a}}$ & $2.3 \pm 0.1^{\mathrm{b}}$ & $3.5 \pm 0.2^{\mathrm{c}}$ & $<0.001$ \\
\hline Total luteal volume, $\mathrm{mm}^{3} \pm \mathrm{SEM}$ & $7,798 \pm 717^{\mathrm{a}}$ & $14,681 \pm 1,333^{\mathrm{b}}$ & $24,519 \pm 1,459^{\mathrm{c}}$ & $<0.001$ \\
\hline Serum $\mathrm{P} 4, \mathrm{ng} / \mathrm{mL} \pm \mathrm{SEM}$ & $6.6 \pm 0.5^{\mathrm{a}}$ & $10.0 \pm 0.9^{\mathrm{b}}$ & $21.7 \pm 3.2^{\mathrm{c}}$ & $<0.001$ \\
\hline
\end{tabular}

${ }^{\mathrm{a}-\mathrm{c}}$ Mean values in the same row with different superscripts differ $(P \leq 0.05)$.

${ }^{1}$ Cows in the control treatment did not receive any treatment. Cows in the hCG7 treatment received 3,300 IU of human chorionic gonadotropin (hCG) $7 \mathrm{~d}$ after the last GnRH (d 7 of the estrous cycle). Cows in the hCG7+13 treatment received 3,300 IU of hCG on $\mathrm{d} 7$ and a second treatment with hCG on d 13 of the estrous cycle.

${ }^{2}$ Only cows with single ovulation at d 0 ( control = 13; hCG7 = 11; hCG7+13=10).

Table 4. Effect of treatment (control, hCG7, and hCG7+13) on luteal and luteolysis dynamics in lactating dairy cows classified with typical estrous cycle with 2 and 3 follicular waves

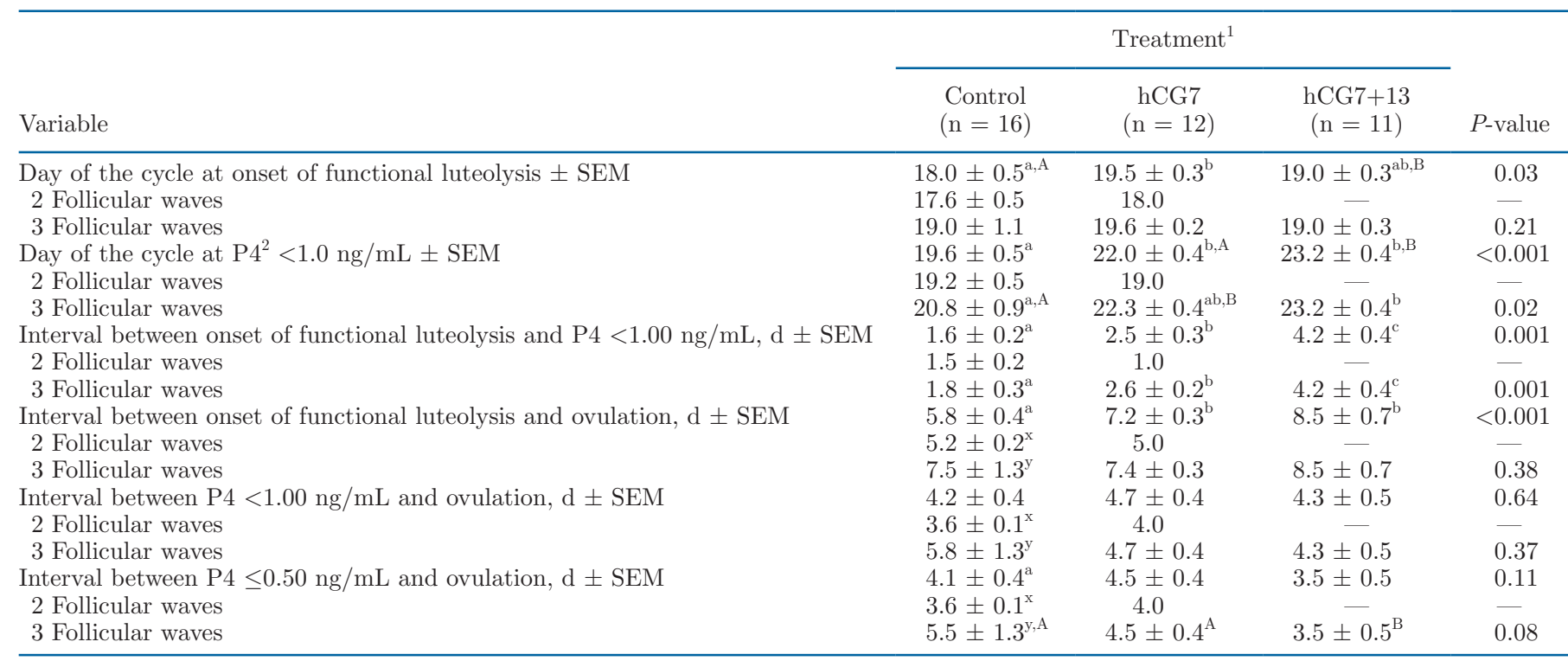

${ }^{\mathrm{a}-\mathrm{c}}$ Mean values in the same row with different superscripts differ $(P \leq 0.05)$.

${ }^{\mathrm{x}, \mathrm{y}}$ Mean values for 2 versus 3 follicular waves in the same variable with different superscripts differ $(P \leq 0.05)$.

${ }^{\mathrm{A}, \mathrm{B}}$ Mean values with different uppercase letters have a tendency $(0.05<P \leq 0.10)$ to differ.

${ }^{1}$ Cows in the control treatment did not receive any treatment. Cows in the hCG7 treatment received 3,300 IU of human chorionic gonadotropin (hCG) $7 \mathrm{~d}$ after the last GnRH (d 7 of the estrous cycle). Cows in the hCG7+13 treatment received 3,300 IU of hCG on d 7 and a second treatment with hCG on d 13 of the estrous cycle.

${ }^{2} \mathrm{P} 4=$ progesterone. 

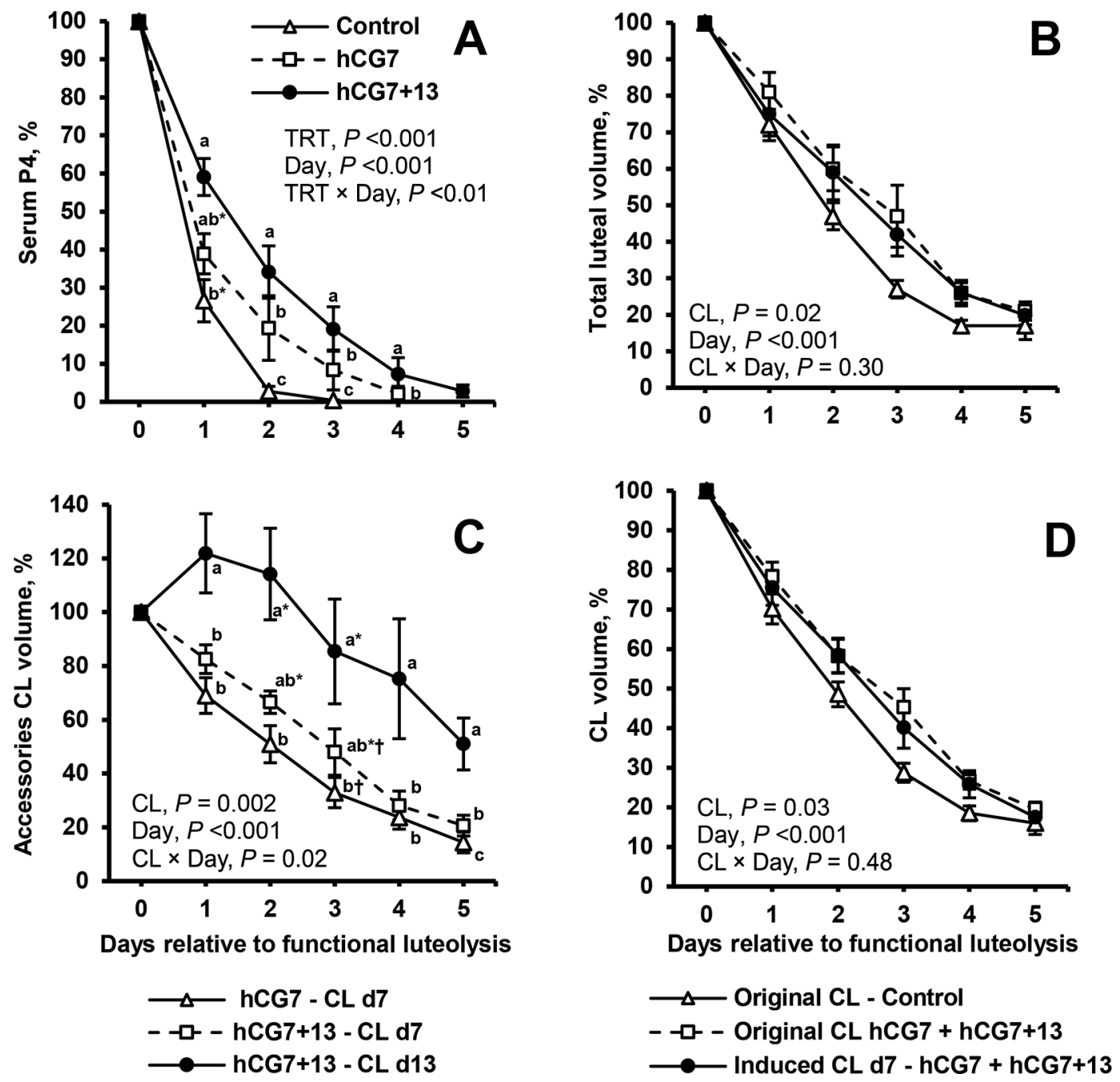

Figure 3. (A) Effect of treatment on the mean ( \pm SEM) percentage of circulating progesterone (P4) concentration; (B) total luteal volume percentage after the onset of functional luteolysis; (C) accessories corpus luteum (CL) volume percentage after the onset of functional luteolysis; (D) comparisons among percentage of original CL volume in the control treatment versus original CL of human chorionic gonadotropin (hCG)treated cows versus d 7 induced CL of hCG-treated cows. The analysis only considers cows with typical estrous cycle (n $=39)$. The circulating P4 concentration and volume of CL on d 0 (onset of luteolysis) was designated as $100 \%$ for each cow. Main effects and their interaction are shown on each panel. Different lowercase letters $(\mathrm{a}-\mathrm{c})$ within a day represent differences between least squares means $(P \leq 0.05)$, and $*$ or $\dagger$ represent a tendency $(0.05<P \leq 0.10)$ for a difference.

with typical cycle, resulting in a prolonged $(P<0.001)$ IOI for cows with delayed ovulation compared with cows with typical cycles (Table 5).

Two cows in control had delayed luteolysis with the onset of luteolysis on d 32 and 34 of the estrous cycle, 4 and 3 follicular waves during the estrous cycle, respectively, and 35 and $38 \mathrm{~d}$ of IOI, respectively (Supplemental Figure S4; http://digital.library.wisc.edu/1793/ 82420; Martins, 2021).

Mean day of first onset of luteolysis for cows with incomplete luteolysis (control, $\mathrm{n}=1$; hCG7, $\mathrm{n}=4$; hCG7+13, n = 5; Figure 5; Supplemental Figure S5; http://digital.library.wisc.edu/1793/82420; Martins, 2021) did not differ $(P=0.14)$ compared with cows with typical cycles (Table 5). However, cows with incomplete luteolysis had complete functional luteolysis $(\mathrm{P} 4<1 \mathrm{ng} / \mathrm{mL})$ later $(P<0.001)$ in the cycle compared with cows with a typical cycle (Table 5 ). All cows with incomplete luteolysis had a second onset of luteolysis to undergo complete functional luteolysis (Figure 5; Table $5)$. The mean \pm SEM for the interval between the first and second onset of luteolysis was $17.4 \pm 2.1 \mathrm{~d}$ (range: 9-29 d). The cow with incomplete luteolysis in control had double ovulation to d $0 \mathrm{GnRH}$ and 2 original ipsilateral CL during the estrous cycle (Table 6). Based on Doppler from the first onset of luteolysis to ovulation, both CL had score $>1$ and did not undergo complete regression. In addition, this cow had serum concentra- 

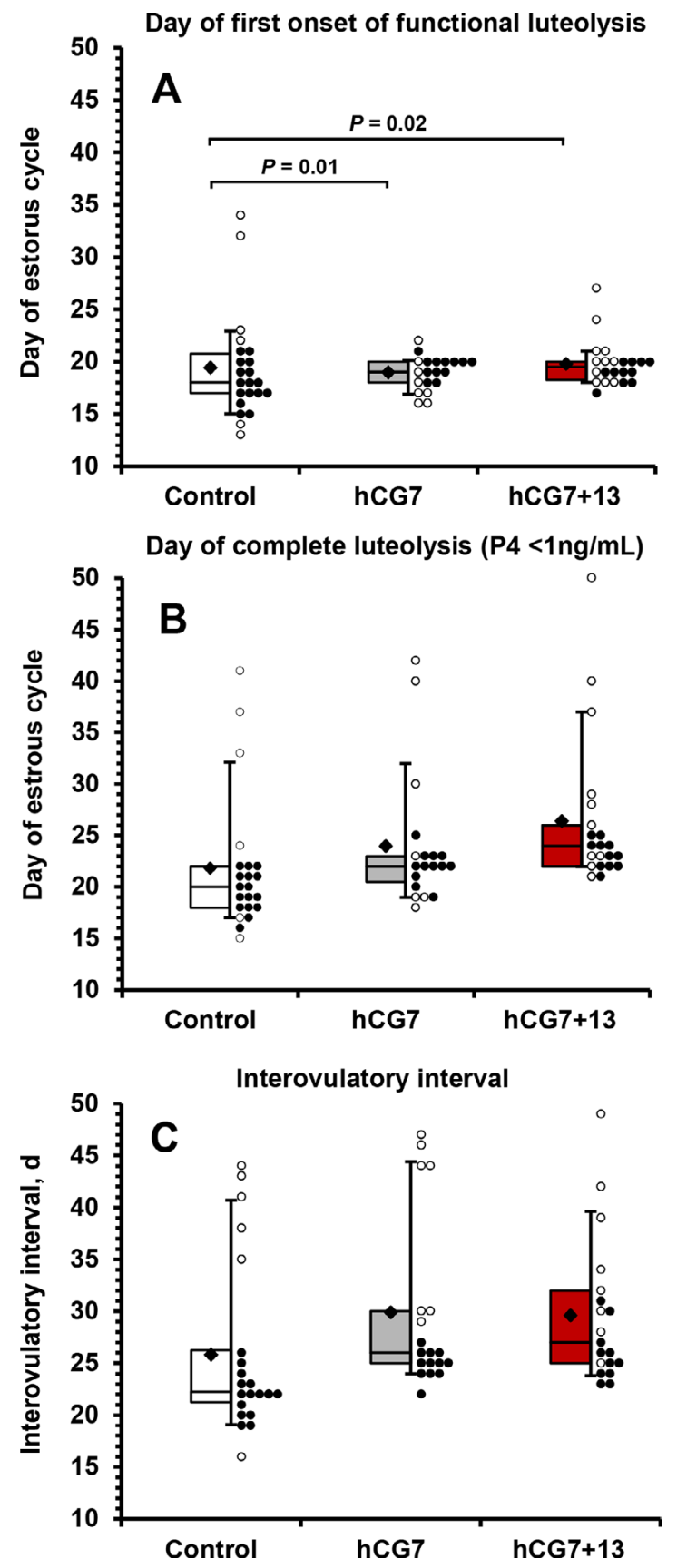

Figure 4. Box-and-whisker plot and scatter plot representing the distribution of cows within treatment for the day of the estrous cycle for the first onset of functional luteolysis (A), completion of luteolysis (B), and interovulatory interval (C). Open dots (o) represent cows with atypical estrous cycle, and solid dots $(\bullet)$ represent cows with typical estrous cycle. In the box-and-whisker plot, diamond markers $(\star)$ indicate the mean within treatments. The bottom of the box indicates the 25th percentile, the middle is the median, and the top represents the 75 th percentile. The bottom and top whiskers denote the 10th and 90th percentiles, respectively. The probability of different variance among treatments for day to the first onset of functional luteolysis is shown in A. Cows in the control did not receive any treatment. Cows in the hCG7 treatment received 3,300 IU of human chorionic gonadotropin (hCG) $7 \mathrm{~d}$ after the last GnRH (d 7 of the estrous cycle). Cows in the hCG7+13 treatment received $3,300 \mathrm{IU}$ of $\mathrm{hCG}$ on $\mathrm{d} 7$ and a second treatment with hCG on d 13 of the estrous cycle. tions of $\mathrm{P} 4>1 \mathrm{ng} / \mathrm{mL}$ between the first and second onset of luteolysis (Supplemental Figure S5; cow \#5498). The other $9 / 10$ cows with incomplete luteolysis had one or more CL regressing (Doppler score $\leq 1$ ) and at least one remaining functional between the first and second onset of luteolysis (Doppler score $>1$; Table 6; Figures 6, 7, and 8; and Supplemental Figure S5). Some cows $(\mathrm{n}=4 / 10)$ had one or more functional CL regression in one ovary, but all CL remained functional in the contralateral ovary between the first and second onset of luteolysis (Table 6; Figures 6 and 7). Surprisingly, n $=6 / 10$ cows had ipsilateral CL, in which one or more CL underwent complete regression, and at least one CL remained functional on the same ovary until the second onset of luteolysis (Table 6; Figures 8 and 9). Figure 10 shows the luteal dynamics of a cow with complete luteolysis classified with a typical cycle.

Although most CL that did not undergo regression were accessory CL, a few original CL also did not undergo complete regression (Table 6). Of the cows with accessory CL (hCG treatments) and incomplete luteolysis $(\mathrm{n}=9)$, one cow had accessory CL regression after the first onset of luteolysis, but the original CL did not regress (Table 6 , cow \#6601). In $\mathrm{n}=6 / 9$ cows, the opposite occurred; the original CL regressed after the first onset of luteolysis, but at least one accessory CL did not regress (Table 6; Figure 6; Supplemental Figure S5). In $\mathrm{n}=2 / 9$ cows, some accessory CL regressed, but the original CL and one accessory CL did not regress (Table 6; Figure 7).

After the first onset of luteolysis, all cows with incomplete luteolysis had an additional follicular wave and a total of 4 follicular waves, except for one cow in the hCG7+13 that had 2 follicular waves after the first onset of luteolysis and a total of 5 follicular waves during the estrous cycle. Cows with incomplete luteolysis had a prolonged $(P<0.001)$ IOI compared with cows with a typical cycle (Table 5). The interval from complete luteolysis to ovulation did not differ $(P=$ 0.41 ) among cows with incomplete luteolysis and typical cycle (Table 5).

\section{DISCUSSION}

This study aimed to determine the effect of $\mathrm{hCG}$ administration either on d 7 only or on both d 7 and 13 on follicular and CL development dynamics and luteolysis during the estrous cycle in noninseminated highproducing lactating Holstein cows. Even though the use of hCG in cattle has been studied for more than 5 decades, to our knowledge, less than a handful of studies with small sample sizes have evaluated the effects of hCG administered during diestrus on ovarian dynamics in noninseminated lactating dairy cows (Helmer and 
Table 5. Differences in luteolysis and estrous cycle characteristics among lactating dairy cows classified with typical estrous cycle, delayed ovulation and incomplete luteolysis

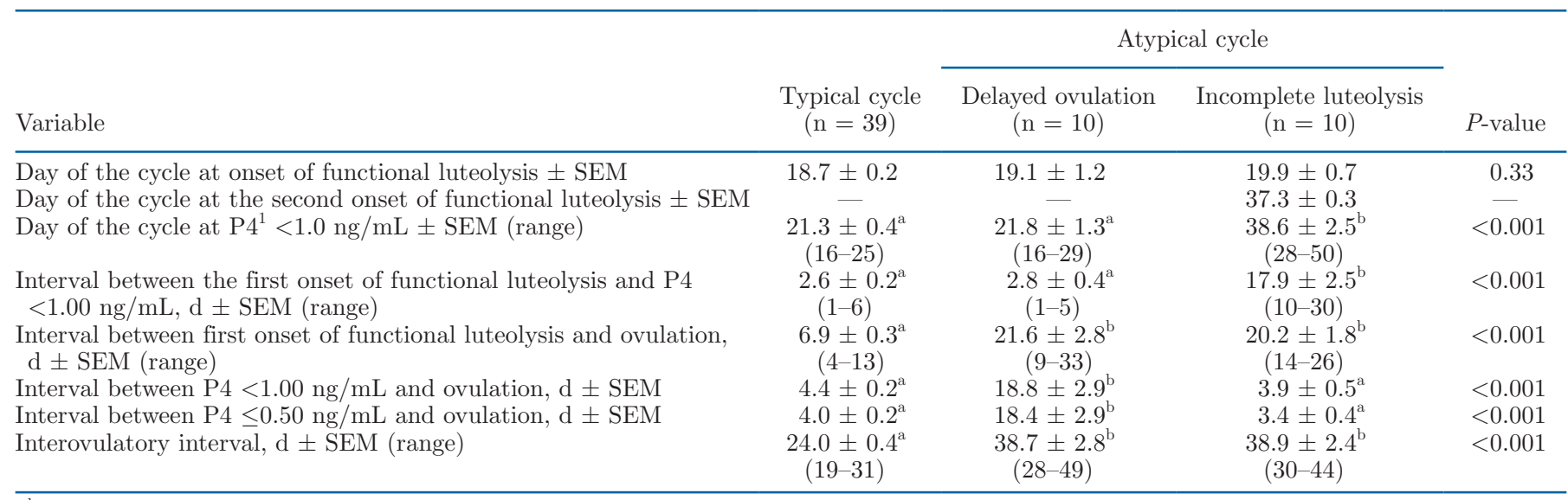

${ }^{\mathrm{a}, \mathrm{b}}$ Mean values in the same row with different superscripts differ $(P \leq 0.05)$.

${ }^{1} \mathrm{P} 4=$ progesterone.

Britt, 1986; Sianangama and Rajamahendran, 1996). Most studies used hCG to induce ovulation of a DF, formation of an accessory $\mathrm{CL}$ and increase circulating $\mathrm{P} 4$ concentration in inseminated cows and heifers (Schmitt et al., 1996b; Santos et al., 2001; Nascimento et al., 2013) or before embryo transfer (Vasconcelos et al., 2011; Niles et al., 2019). These studies aimed to test the effect of increased circulating $\mathrm{P} 4$ concentrations induced by hCG on early embryo development (Rizos et al., 2012) and fertility in cattle. However, the effect of the formation of an accessory CL after hCG treatment on estrous cycle characteristics in nonpregnant inseminated cows is unclear due to the possible presence of an embryo and the effects of interferon tau on the timing of the luteolysis process. Even with the confounding effect of AI and ET, Niles et al. (2019) indicated that nonpregnant heifers after AI and ET that were treated with hCG on d 7 had a delay in luteolysis compared with nonpregnant untreated heifers. In agreement, a recent study from our laboratory using noninseminated

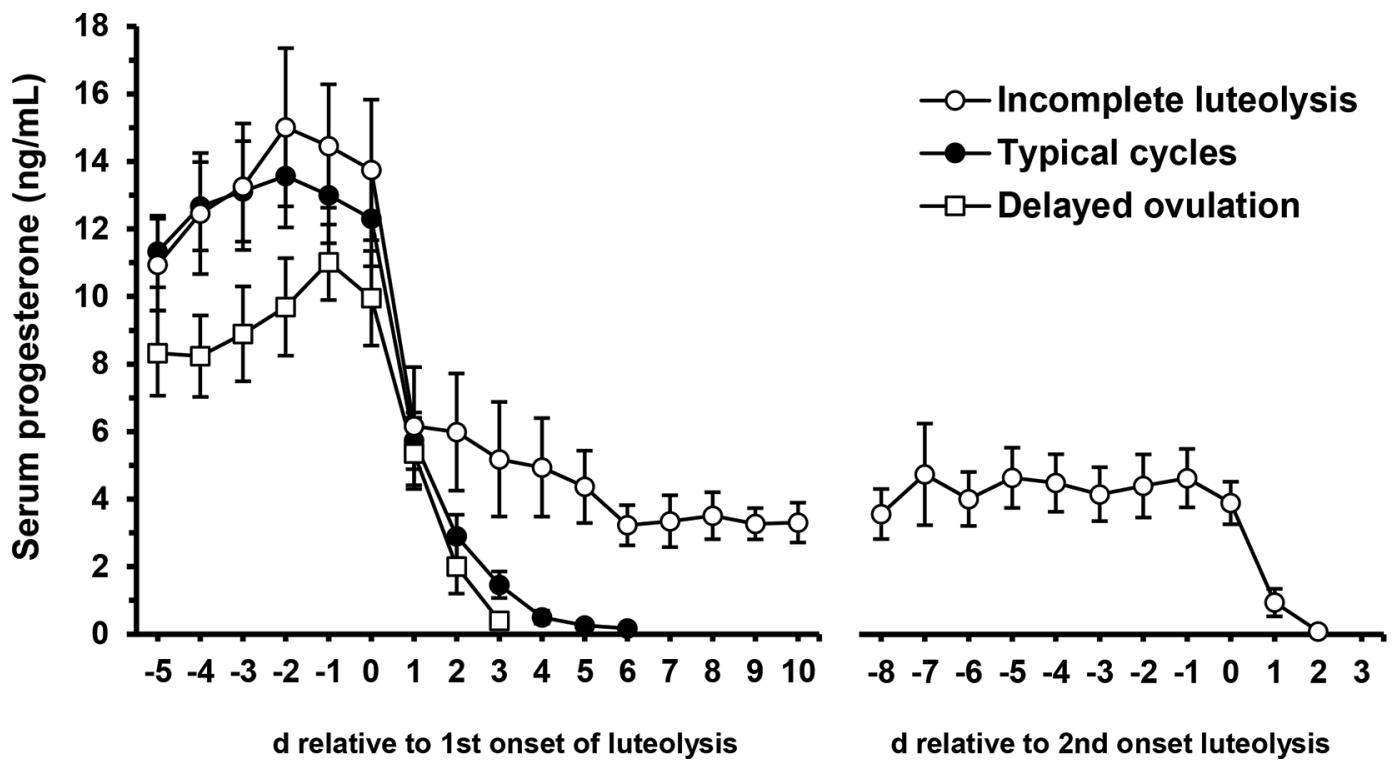

Figure 5. Mean $( \pm$ SEM) serum progesterone concentrations relative to the first onset of luteolysis in lactating dairy cows with typical estrous cycle $(\mathrm{n}=39)$ and relative to first and second onset of luteolysis in lactating dairy cows with atypical estrous cycle with incomplete luteolysis $(\mathrm{n}=8)$ or delayed ovulation $(\mathrm{n}=9)$. Atypical estrous cycle with incomplete luteolysis: cows with incomplete functional luteolysis that did not complete corpus luteum regression by $6 \mathrm{~d}$ after the first onset of luteolysis. Atypical estrous cycle with delayed ovulation: cows with the dominant follicle or future dominant follicle at the time of luteolysis that did not ovulate. 

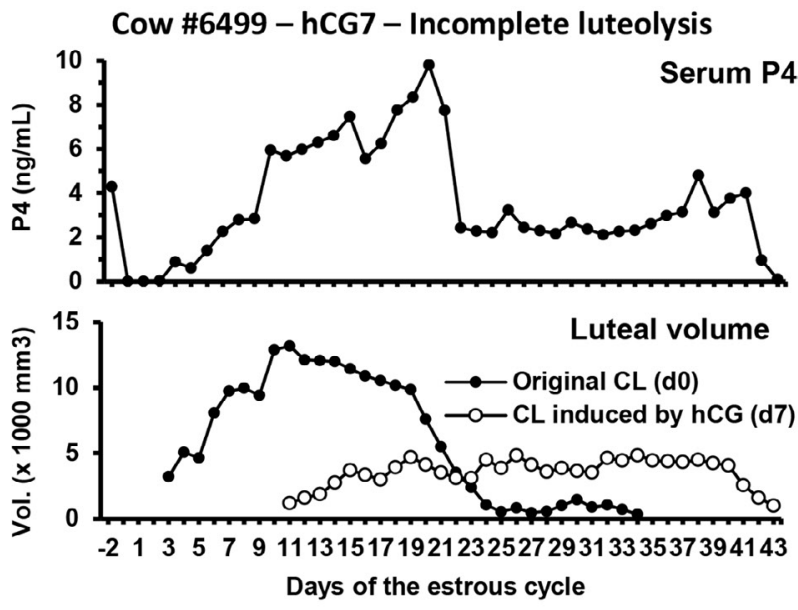

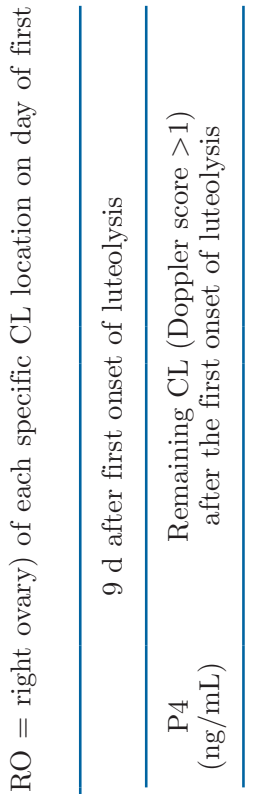

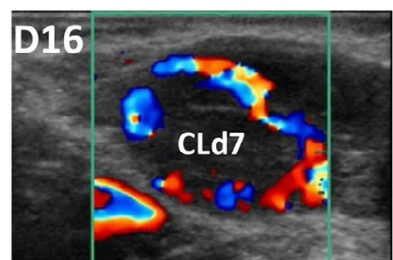

RIGHT OVARY
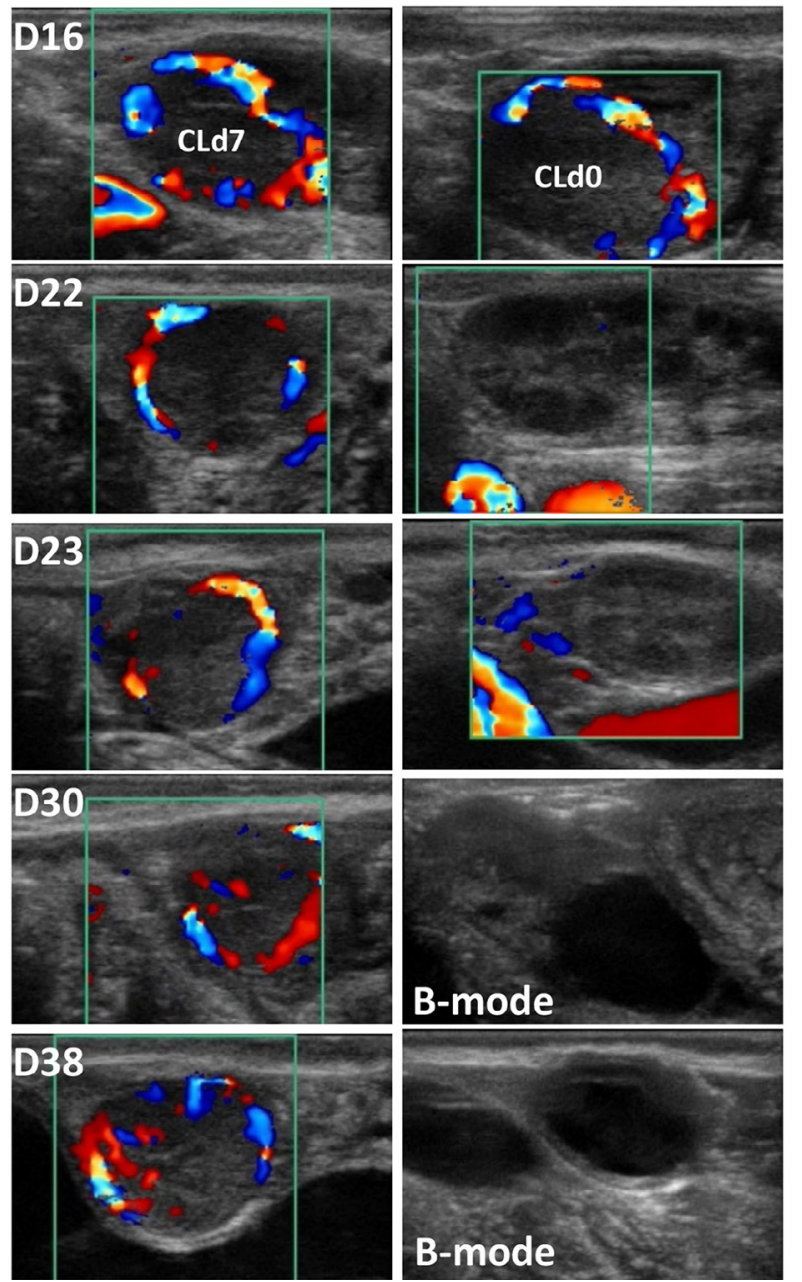

Figure 6. Patterns of luteal development (luteal volume) and serum progesterone ( $\mathrm{P} 4)$ concentration, and ovarian sonographic B-Mode and color Doppler images of corpora lutea (CL) of a lactating Holstein cow $(\# 6,499)$ treated with human chorionic gonadotropin $(\mathrm{hCG})$ on $\mathrm{d}$ 7 of the estrous cycle (hCG7) and classified with an atypical estrous cycle due to incomplete luteolysis. The original CLd0 on the left ovary regressed after the first onset of luteolysis, but the contralateral CLd7 did not regress. CLd0 $=$ original CL; CLd7 $=$ accessory CL formed after hCG treatment on $\mathrm{d} 7$.

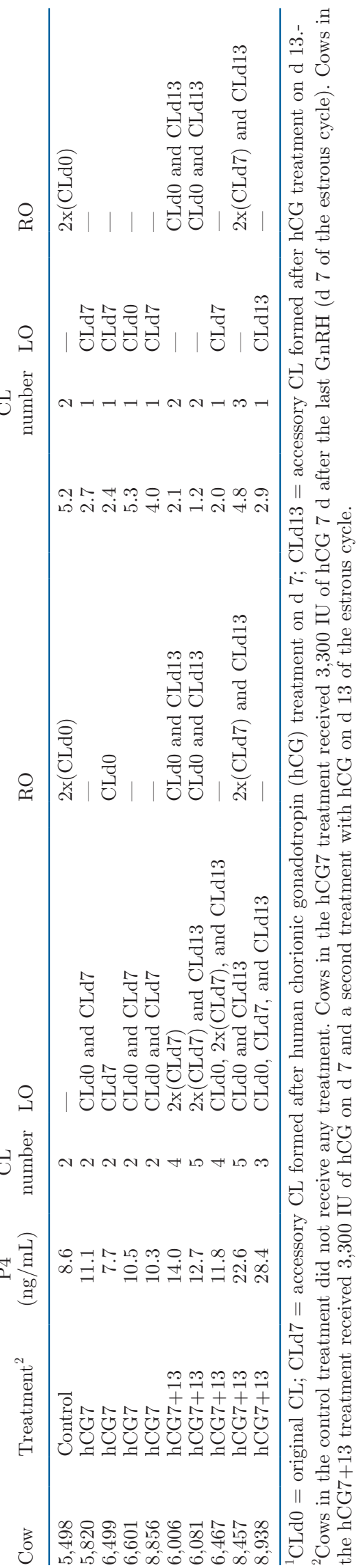


cows determined that a single administration of 3,300 IU of hCG from d 5 to 7 of the estrous cycle reduced the proportion of multiparous cows returning to estrous and prolonged the estrous cycle (Cunha et al., 2021). In farms that use detection of estrus to rebreed cows and heifers post-AI, the use of hCG post-AI could affect their reproductive performance. Thus, to continue using this tool to enhance fertility of lactating dairy cows, it is necessary to understand the physiological effects of the use of hCG to induce ovulation and accessory CL formation during diestrus.

In the present study, we used 3,300 IU hCG to induce ovulation of a DF and the formation of accessory CL in noninseminated lactating Holstein cows, which resulted in a high ovulation rate; only 2 of $42(4.8 \%)$ cows did not ovulate and $3 / 64(4.6 \%)$ hCG treatments failed to induce ovulation. We also successfully increased serum
P4 concentrations during diestrus due to increased total luteal volume by growth of the original CL and formation of new accessory CL, consistent with other studies (Sianangama and Rajamahendran, 1992, Fricke et al., 1993, Santos et al., 2001). Our results indicated that hCG administered on $\mathrm{d} 7$ caused an increase in the original CL volume that was maintained during most of the diestrus period. The second administration of $\mathrm{hCG}$ in $\mathrm{hCG} 7+13$ cows allowed maintenance of the increased volume of the original CL after d 13 and extension of the greater volume before the onset of functional luteolysis compared with cows receiving hCG7. Schmitt et al. (1996a) determined that the original CL of cows treated with hCG on d 5 had an increase in the size of small and large luteal cells at d 17 of the cycle compared with control cows (saline), but they did not find an increase in the number of small and large luteal
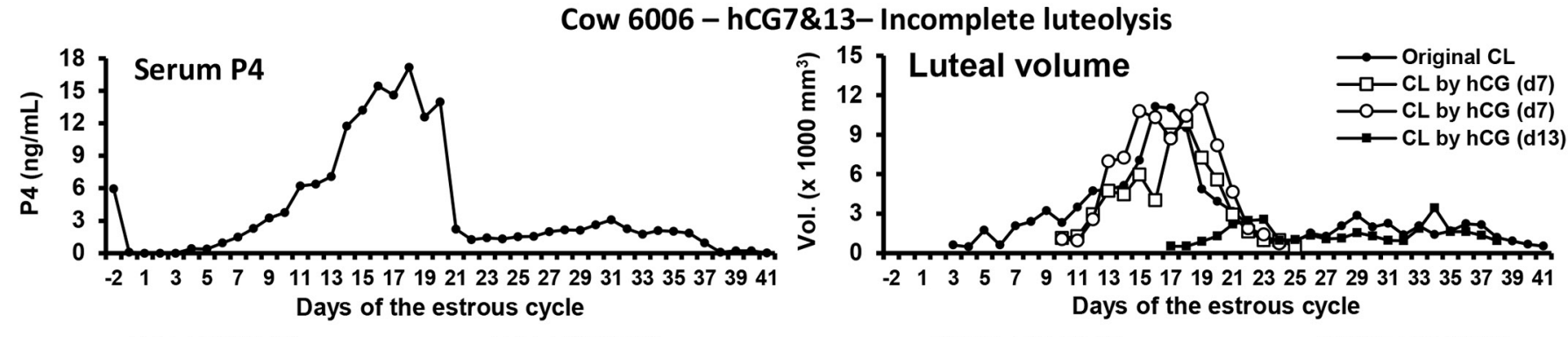

LEFT OVARY
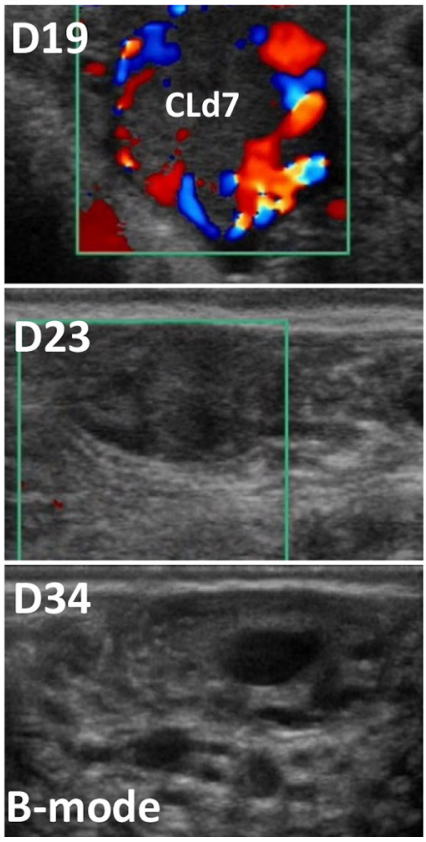

LEFT OVARY
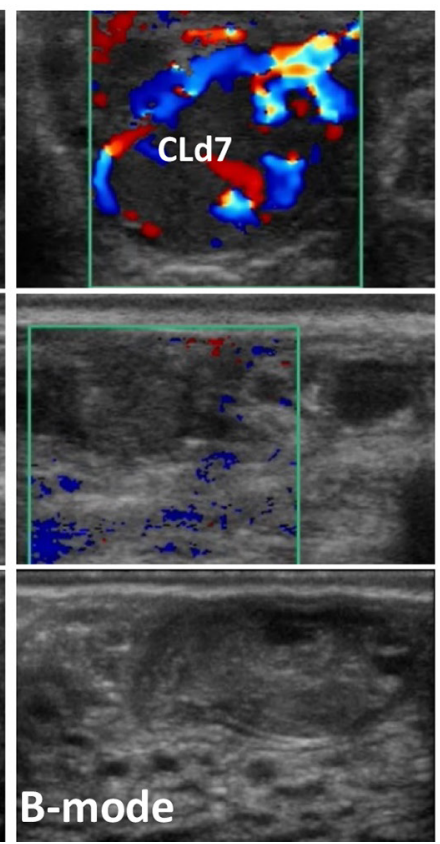

RIGHT OVARY
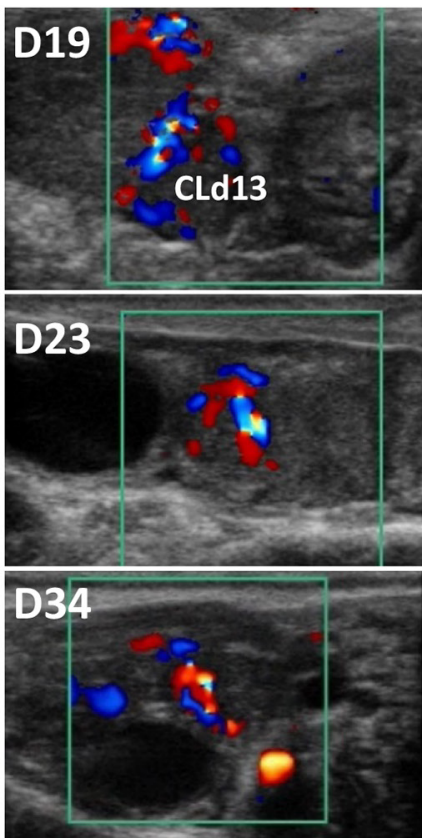

RIGHT OVARY
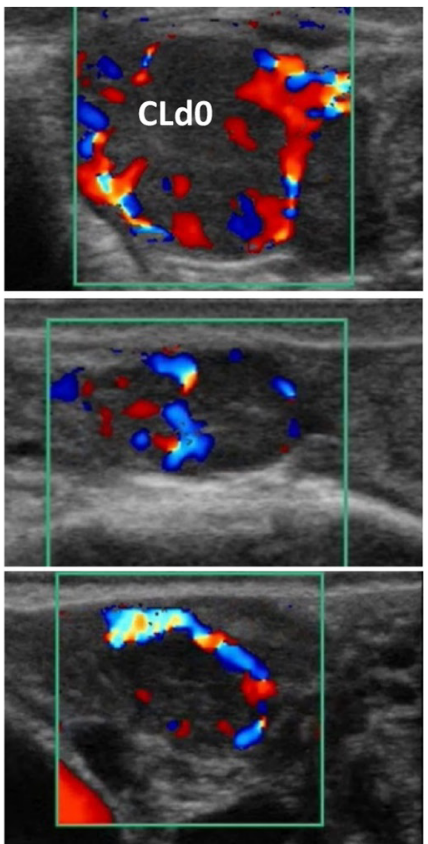

Figure 7. Patterns of luteal development (luteal volume) and serum progesterone (P4) concentration, and ovarian sonographic B-Mode and color Doppler images of corpora lutea (CL) of a lactating Holstein cow $(\# 6,006)$ treated with human chorionic gonadotropin (hCG) on d 7 and 13 of the estrous cycle $(\mathrm{hCG} 7+13)$ and classified with an atypical estrous cycle due to incomplete luteolysis. Two accessories CLd7 in the left ovary regressed after the first onset of luteolysis, but the contralateral original CLd0 and accessory CLd13 did not regress. CLd0 = original CL; CLd7 $=$ accessory CL formed after hCG treatment on d 7; CLd13 = accessory CL formed after hCG treatment on d 13. 
cells. In the present study, the increase in the volume of original CL for cows treated with hCG may be explained by a hypertrophy effect of hCG on luteal cells. Although original CL volume in hCG7 and hCG7+13 cows decreased before the onset of functional luteolysis, serum P4 concentration was maintained during the same period, most likely due to the development and increase in the size of the accessory CL in the same period.

A greater proportion of cows treated with hCG on d 7 had estrous cycles with 3 follicular waves than control cows, confirming our first hypothesis. Inducing ovulation of the first-wave DF using hCG on $\mathrm{d} 7$ of the estrous cycle led to an earlier emergence of the second wave on d 8 to 9 , subsequent regression of the second-wave DF, and emergence of the third wave on d 16 to 17 . The days of follicular wave emergence were similar to cows with noninduced 3 follicular waves estrous cycles previously reported, with emergence of the second wave on $\mathrm{d} 8$ or 9 of the estrous cycle and the third wave on d 16 or 17 (Ginther et al., 1989; Sartori et al., 2004). The second follicular wave emergence in control cows with 2 waves was later in the cycle (d 11.7 $\pm 0.6)$. The earlier emergence of the second follicular wave and the increased circulating $\mathrm{P} 4$ concentration in hCG-treated cows most likely led to early atresia of the second-wave DF, before luteolysis, and emergence of a third follicular wave in the hCG7 cows. In hCG7+13 cows, the third-wave emergence was already expected to occur after induced ovulation of the second-wave DF with hCG on d 13 of the cycle.

Our second hypothesis that cows treated with hCG would have a prolonged IOI than control cows was also confirmed. The longer IOI for cows treated with $\mathrm{hCG}$ seemed to relate primarily to the increase in the proportion of cows with 3 follicular waves. Previous studies reported that cows and heifers with 3-follicular wave cycles have longer IOI than 2-wave cycles (Ginther et al., 1989; Diaz et al., 1998; Bleach et al., 2004). The longer IOI has also been related to an earlier emergence of the second wave and later onset of luteolysis in nontreated cows and heifers (Savio et al., 1990; Jaiswal et al., 2009), as occurred in hCG7 3-waves cows in the present study. After the onset of luteolysis, these cows took longer to ovulate than control cows because the third-wave DF had to grow large enough to produce sufficient E2 to induce a pre-ovulatory GnRH surge. The occurrence of 3 follicular waves and later onset of luteolysis were crucial factors in prolonging the IOI in our study.

The initiation of luteolysis in the bovine is characterized by endometrial pulse release of $\mathrm{PGF}_{2 \alpha}$ in response to hypothalamic oxytocin (reviewed by McCracken et al., 1999). The regulation of $\mathrm{PGF}_{2 \alpha}$ secretion is a result of an interaction among circulating concentrations of estradiol-17 $\beta$ (E2), P4, and oxytocin (OXT) and the changes in their respective receptors in the endometrium (Flint et al., 1994; Robinson et al., 2001). It seems

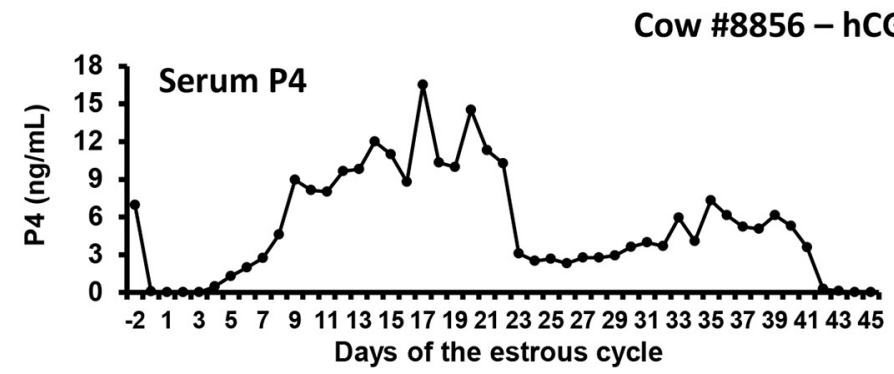

LEFT OVARY
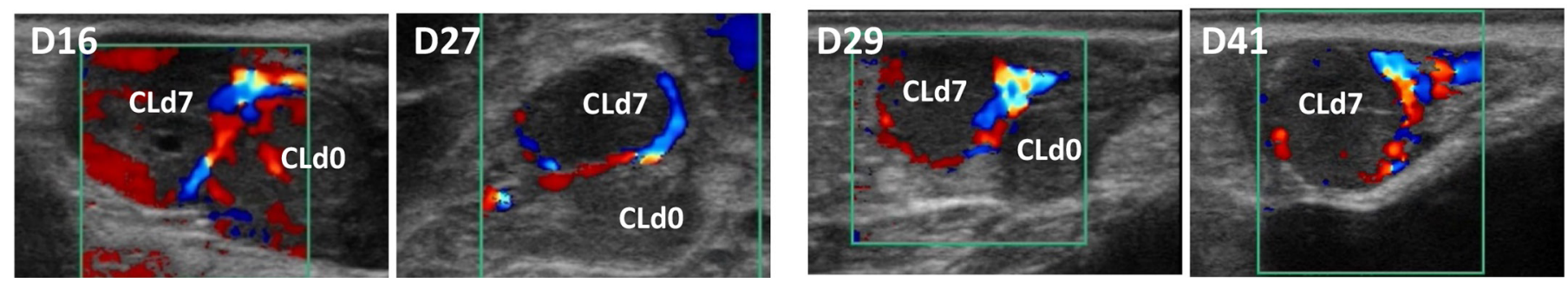

Figure 8. Patterns of luteal development (luteal volume) and serum progesterone (P4) concentration, and ovarian color Doppler images of corpora lutea (CL) of a lactating Holstein cow $(\# 8,856)$ treated with human chorionic gonadotropin (hCG) on d 7 of the estrous cycle (hCG7) and classified with an atypical estrous cycle due to incomplete luteolysis. The original CLd0 in the left ovary regressed after the first onset of luteolysis, but the ipsilateral accessory CLd7 did not regress. This cow did not have any CL on the right ovary. CLd0 = original CL; CLd7 $=$ accessory CL formed after hCG treatment on $\mathrm{d} 7$. 

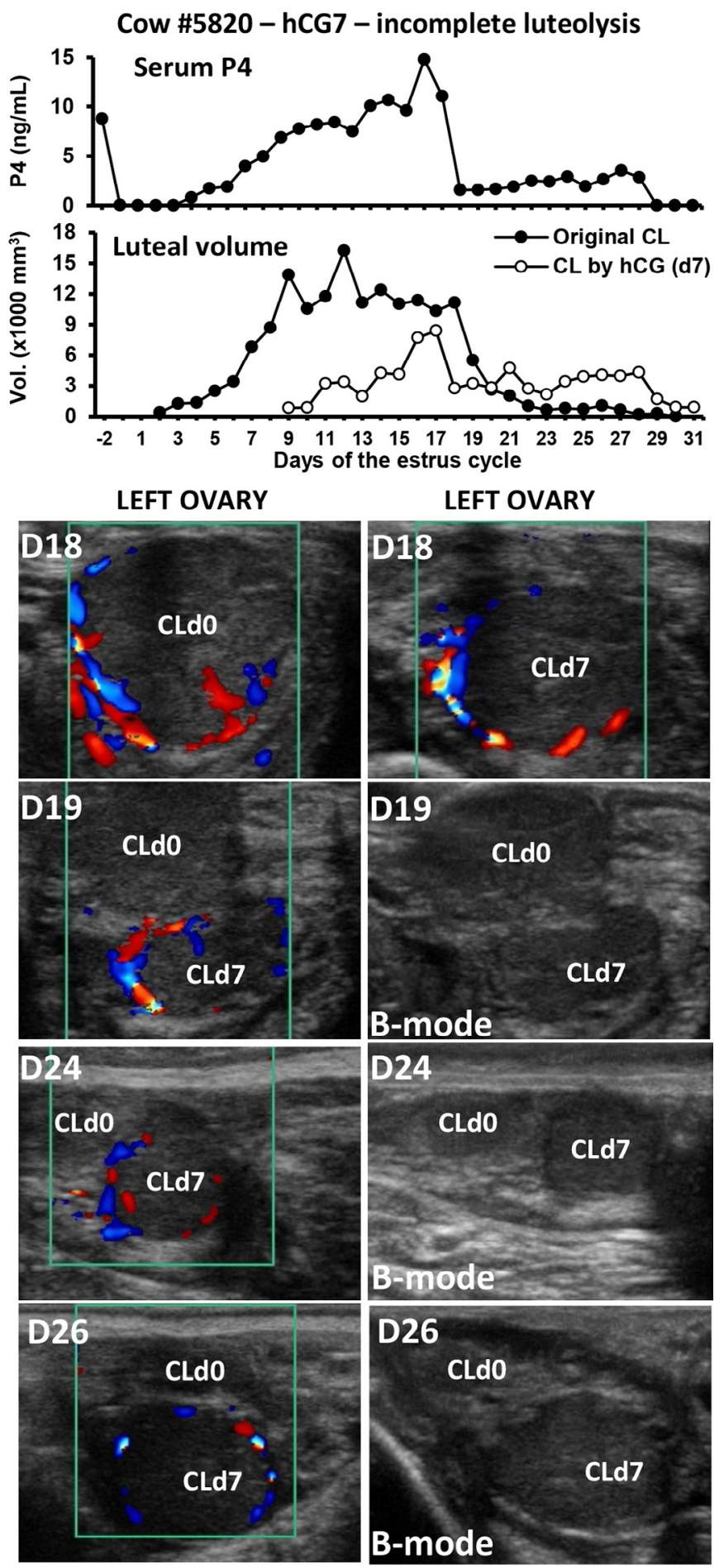

Figure 9. Patterns of luteal development (luteal volume) and serum progesterone $(\mathrm{P} 4)$ concentration, and ovarian sonographic and color Doppler images of corpora lutea (CL) of a lactating Holstein cow $(\# 5,820)$ treated with human chorionic gonadotropin $(\mathrm{hCG})$ on d 7 of the estrous cycle (hCG7) and classified with an atypical estrous cycle due to incomplete luteolysis. The original CLd0 in the left ovary regressed after the first onset of luteolysis, but the ipsilateral accessory CLd7 did not regress. This cow did not have any CL on the right ovary. CLd0 = original CL; CLd7 = accessory CL formed after hCG treatment on $\mathrm{d} 7$. that both circulating concentrations of E2 produced by the DF and the endometrial E2 responsiveness are the main factors that may initiate upregulation of OXT receptors (OXTR) and timing of luteolysis (Domingues et al., 2020). Araujo et al. (2009) successfully prevented the rise of follicular E2 and prolonged the luteal phase in dairy heifers after daily follicle ablation between d 9 and 15 of the estrous cycle. The prolonged luteal phase caused by successive follicular aspirations was reversed with exogenous E2 administration on d 13 and 15 of the estrous cycle. In a recent study, Domingues et al. (2020) temporally associated a later upregulation of endometrial OXT mRNA with later onset of luteolysis in heifers with 3 waves during the cycle. In that study, the

\section{Cow \#6450 - hCG7\&13 - Typical cycle}
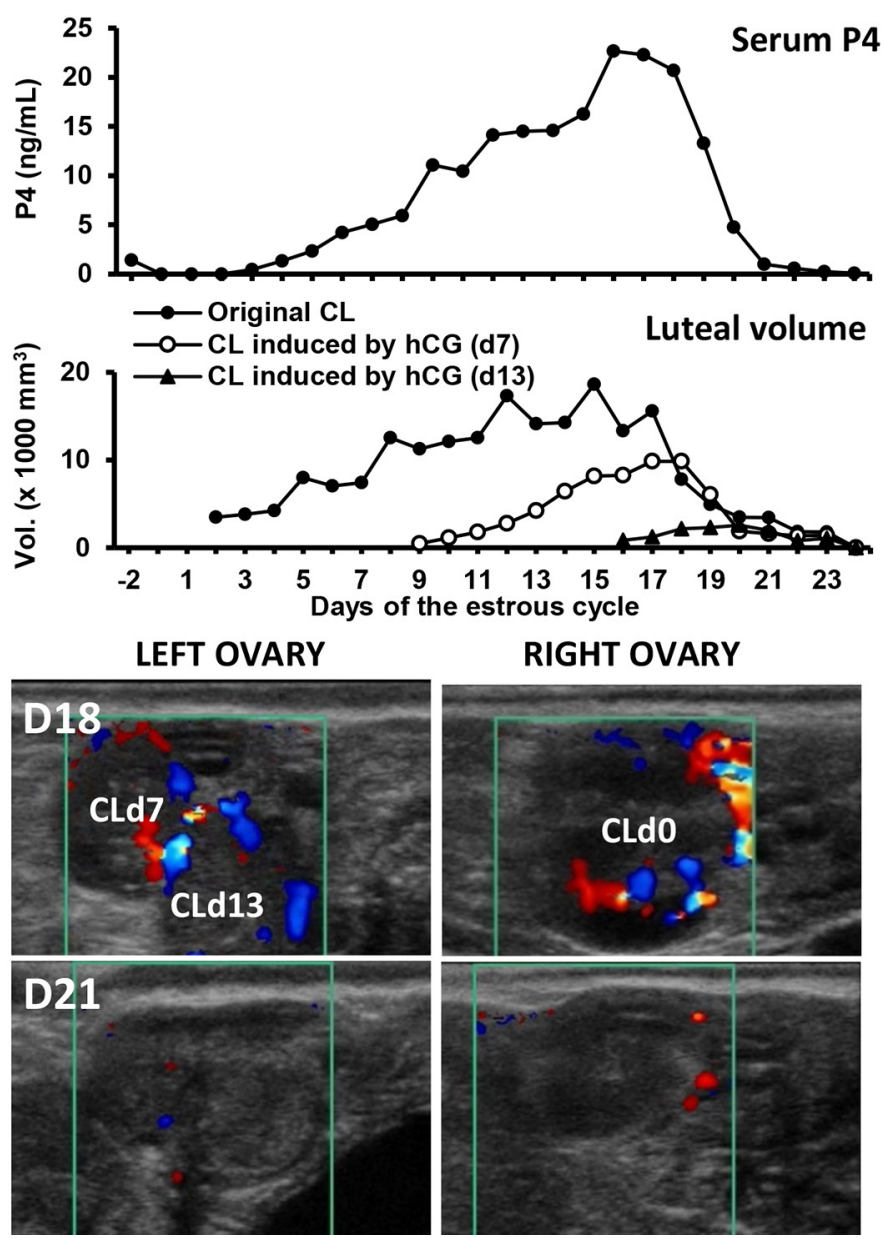

RIGHT OVARY

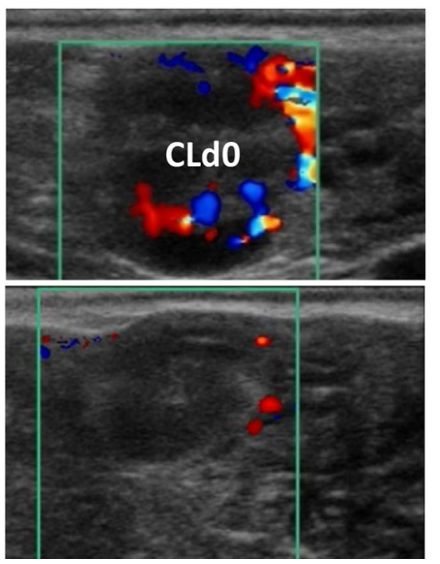

Figure 10. Patterns of luteal development (luteal volume) and serum progesterone (P4) concentration, and ovarian sonographic color Doppler images of the corpora lutea (CL) of a lactating Holstein cow $(\# 6,450)$ treated with human chorionic gonadotropin $(\mathrm{hCG})$ on $\mathrm{d} 7$ and 13 of the estrous cycle $(\mathrm{hCG} 7+13)$ and classified with a typical estrous cycle. CLd0 = original CL; CLd7 = accessory CL formed after $\mathrm{hCG}$ treatment on d 7; CLd13 = accessory CL formed after hCG treatment on d 13 . 
author suggested that in heifers with 2 or 3 waves cycle, the downregulation of $\mathrm{P} 4$ and estradiol- $\beta$ receptors removes their inhibitory effects on estradiol- $\alpha$ receptors at a similar time during the cycle. Their hypothesis was that in cycles with 3 follicular waves, the second-wave DF lost dominance and E2 secretory capacity before estradiol- $\alpha$ receptors could be activated. In addition, upregulation of OXTR was delayed until adequate circulating E2 concentrations from either the second or third follicular wave activate estradiol- $\alpha$ receptors. The difference in day for onset of luteolysis and the decreased variation in the onset of functional luteolysis observed in our study for cows treated with hCG7 and hCG7+13 compared with control support the role of follicles in the timing of luteolysis onset in cattle. It also confirmed our final hypothesis that cows treated with hCG on d 7 and 13 would have follicles from the third wave growing in such synchrony that there would be a reduction in variation for the onset of luteolysis. Decreasing this variance could benefit rebreeding strategies, especially resynchronization of ovulation for timed-AI protocols before pregnancy diagnosis that aim to control the follicular wave of the preovulatory follicle with a GnRH injection (Giordano et al., 2012, Baruselli et al., 2018, Palhão et al., 2020).

One surprising finding in this study was the protracted interval for complete functional luteolysis in hCGtreated cows. Previous reports using lactating Holstein cows and heifers indicated that natural complete functional luteolysis takes between 1 and $2 \mathrm{~d}$ (Sartori et al., 2004; Ginther et al., 2007), which is consistent with our findings in control cows. For cows in the treatment hCG $7+13$, our results suggest that the youngest accessory CL induced by hCG on $\mathrm{d} 13$ of the cycle and $\sim 6$ $\mathrm{d}$ old at the onset of luteolysis might have prolonged the luteolysis process. A single administration of $\mathrm{GnRH}$ agonist ( $5 \mu \mathrm{g}$ of buserelin) from d 12 to 16 of the estrous cycle also prolonged the average length of the estrous cycle, indicating that cows with accessory CL formed later in diestrus might have induced a later luteolysis onset (Macmillan et al., 1985). Moreover, studies have indicated that CL $7 \mathrm{~d}$ old or younger may not be completely responsive to the administration of exogenous $\mathrm{PGF}_{2 \alpha}$ (Tsai and Wiltbank, 1998; Nascimento et al., 2014). In some cows in the hCG treatments, more endometrial pulses of $\mathrm{PGF}_{2 \alpha}$, which occur in intervals of 7 to 12 h (Ginther et al., 2007, 2010), may have been required to achieve complete luteolysis. Yet, this would only partially explain the prolonged luteolysis interval since hCG7 cows with older accessory CL ( 12 d old) at the onset of luteolysis also had prolonged luteolysis.

Another indication of tardy complete luteolysis was the slower decrease in the volume of the original CL in both hCG7 and hCG7+13 compared with controls. These results suggested a longer luteolysis of older CL in cows treated with hCG. Furthermore, hCG treatment on $\mathrm{d} 5$ of the estrous cycle has been reported to increase the proportion of small and large luteal cells of the original CL in earlier stages of development at d 17 compared with untreated cows (Schmitt et al., 1996a). They also suggested that hCG may have delayed the progression of luteal cells through the stages of development that lead to involution and regression (Schmitt et al., 1996a). Perhaps this delay in small and large luteal cell development has altered the ability of the CL to undergo complete regression after endometrial $\mathrm{PGF}_{2 \alpha}$ pulses. Other factors that may have contributed to the prolonged functional luteolysis in $\mathrm{hCG}$ treatment were the greater CL number and total luteal volume for cows at the onset of luteolysis. The $\sim 50 \%$ and $\sim 330 \%$ greater mean serum $\mathrm{P} 4$ concentrations at onset of luteolysis for hCG7 and hCG7+13, respectively, than control cows, does not seem to explain the prolonged luteolysis process in cows treated with $\mathrm{hCG}(1.6 \pm 0.2$ d vs. $2.5 \pm 0.2 \mathrm{~d}$ vs. $4.2 \pm 0.2 \mathrm{~d}$ for control, hCG7 and hCG $7+13$, respectively) because the clearance rate of circulating P4 occurs relatively fast in lactating dairy cows (Sangsritavong et al., 2002). The average half-life of P4 in dairy cows is approximately 35 min (Miller et al., 1963).

All these potential factors that extended the luteolytic process in hCG-treated cows could also have impacted the capacity of cows to complete CL regression and undergo complete functional luteolysis. A previous study identified delayed or incomplete luteolysis induced by exogenous $\mathrm{PGF}_{2 \alpha}$ analogs in lactating dairy cows (Martins et al., 2011). Also, Greco et al. (2018) identified approximately $18 \%$ of lactating Holstein cows with no spontaneous luteolysis (P4>1.00 ng/ $\mathrm{mL}$ ) by $\mathrm{d} 23$ of the estrous cycle. However, those cows did not have accessory CL and were not followed after d 23 of the estrous cycle. It appears that cows with no luteolysis in that study may not have had luteolytic PGFM pulses and a significant decrease in circulating P4 concentrations by d 23 of the estrous cycle (Greco et al., 2018). In the present study, we collected data from all cows until subsequent spontaneous ovulation. All cows in our study had an onset of luteolysis with a significant decrease in circulating $\mathrm{P} 4$ concentrations during the estrous cycle, early or late, that most likely characterize luteolytic $\mathrm{PGF}_{2 \alpha}$ pulses. Ten cows ( $\mathrm{n}=$ $10 / 62$ ) did not achieve $\mathrm{P} 4<1.00 \mathrm{ng} / \mathrm{mL}$ after the onset of luteolysis and had incomplete luteolysis. Most of them were in hCG treatments $(\mathrm{n}=9 / 10)$, suggesting that induction of accessory CL using hCG may disrupt some physiological processes essential for completion of 
functional luteolysis. The majority of cows with incomplete luteolysis $(\mathrm{n}=9 / 10)$ also had one or more CL with complete structural regression based on Doppler evaluations and a significant decrease in circulating concentrations of $\mathrm{P} 4$ approximately d 21 of the estrous cycle. Differently, cows with delayed luteolysis did not significantly decrease serum P4 concentration until approximately d 33 of the estrous cycle. These results indicated that cows with incomplete luteolysis had luteolytic endometrial pulses of $\mathrm{PGF}_{2 \alpha}$, but at least one CL did not respond to the $\mathrm{PGF}_{2 \alpha}$ pulses either because the pulses were inadequate to induce complete luteolysis or the $\mathrm{CL}$ was refractory to $\mathrm{PGF}_{2 \alpha}$ action. All cows with incomplete luteolysis needed a second onset of luteolysis to undergo complete functional luteolysis. In addition, it appears that another luteal phase with similar duration to a normal estrous cycle was necessary to prepare the endometrium for the second onset of luteolysis.

Besides cows with incomplete or delayed luteolysis, we also identified cows with delayed ovulation and a short estrous cycle. These classifications of atypical estrous cycle have been reported in previous studies (Savio et al., 1990; Sartori et al., 2004). In the present experiment, most cows with atypical estrous cycles had delayed ovulation $(10 / 23)$ or incomplete luteolysis $(10 / 23)$. Moreover, the majority of them were in hCG treatments $(17 / 20)$, suggesting that induction of accessory CL with hCG during diestrus may disrupt luteolysis and ovulation. These results also agree with a recent study from our laboratory that determined that a single hCG treatment from d 5 to 7 of the estrous cycle decreased the proportion of lactating multiparous Holstein cows returning in estrus until d 32 of the cycle (Cunha et al., 2021). In addition, cows returning to estrus after treatment had a prolonged estrous cycle (Cunha et al., 2021). Thus, the effects of hCG on the estrous cycle dynamics must be considered in farms that use detection of estrus as a rebreeding strategy and use hCG post-AI or before ET to improve fertility (Nascimento et al., 2013; Niles et al., 2019).

In conclusion, hCG administration on $\mathrm{d} 7$ and $\mathrm{d} 7$ and 13 of the estrous cycle augmented the original CL volume, increased serum concentration of P4 during diestrus and the proportion of cows with 3 follicular waves, and decreased the variability in the onset of luteolysis. Nevertheless, hCG treatments also prolonged luteolysis and IOI, and increased the incidence of cows with impaired luteolysis and delayed ovulation. These data indicate that forming accessory CL with the use of hCG disrupted natural luteolysis and ovulation, which are critical physiological events that regulate estrous cycle length.

\section{ACKNOWLEDGMENTS}

We thank the University of Wisconsin-Madison for this project's partial funding. A special thanks to Robert Heinz, Susan Murkley and Hattie Weissmann from Emmons Blaine Dairy Cattle Center (Arlington, WI), Shan Betzold and Deidre Kannenberg from US Dairy Forage Research Center (Prairie du Sac, WI), and other farm employees for their help conducting this experiment. We also thank Merck Animal Health (Madison, NJ) for donating Chorulon used in this study. The authors have not stated any conflicts of interest.

\section{REFERENCES}

Araujo, R. R., O. Ginther, J. C. Ferreira, M. M. Palhão, M. A. Beg, and M. C. Wiltbank. 2009. Role of follicular estradiol-17beta in timing of luteolysis in heifers. Biol. Reprod. 81:426-437. https:// doi.org/10.1095/biolreprod.108.073825.

Baruselli, P. S., J. N. S. Sales, R. V. Sala, L. M. Vieira, and M. F. Sá Filho. 2018. History, evolution and perspectives of timed artificial insemination programs in Brazil. Anim. Reprod. 9:139-152.

Besbaci, M., A. Abdelli, J. Minviel, I. Belabdi, R. Kaidi, and D. Raboisson. 2020. Association of pregnancy per artificial insemination with gonadotropin-releasing hormone and human chorionic gonadotropin administered during the luteal phase after artificial insemination in dairy cows: A meta-analysis. J. Dairy Sci. 103:2006-2018. https://doi.org/10.3168/jds.2019-16439.

Bisinotto, R. S., I. J. Lean, W. W. Thatcher, and J. E. P. Santos. 2015. Meta-analysis of progesterone supplementation during timed artificial insemination programs in dairy cows. J. Dairy Sci. 98:24722487. https://doi.org/10.3168/jds.2014-8954.

Bisinotto, R. S., E. S. Ribeiro, F. S. Lima, N. Martinez, L. F. Greco, L. F. S. P. Barbosa, P. P. Bueno, L. F. S. Scagion, W. W. Thatcher, and J. E. P. Santos. 2013. Targeted progesterone supplementation improves fertility in lactating dairy cows without a corpus luteum at the initiation of the timed artificial insemination protocol. J. Dairy Sci. 96:2214-2225. https://doi.org/10.3168/jds.2012-6038.

Bleach, E. C. L., R. G. Glencross, and P. G. Knight. 2004. Association between ovarian follicle development and pregnancy rates in dairy cows undergoing spontaneous oestrous cycles. Reproduction 127:621-629. https://doi.org/10.1530/rep.1.00190.

Cabrera, E. M., M. R. Lauber, E. M. Peralta, T. R. Bilby, and P. M. Fricke. 2021. Human chorionic gonadotropin dose response for induction of ovulation 7 days after a synchronized ovulation in lactating Holstein cows. JDS Commun. 2:35-40. https://doi.org/ 10.3168/jdsc.2020-0024.

Cardoso Consentini, C. E., M. C. Wiltbank, and R. Sartori. 2021. Factors that optimize reproductive efficiency in dairy herds with an emphasis on timed artificial insemination programs. Animals (Basel) 11:301. https://doi.org/10.3390/ani11020301.

Carvalho, P. D., V. G. Santos, J. O. Giordano, M. C. Wiltbank, and P. M. Fricke. 2018. Development of fertility programs to achieve high 21-day pregnancy rates in high-producing dairy cows. Theriogenology 114:165-172. https://doi.org/10.1016/j.theriogenology .2018.03.037.

Cunha, T. O., W. Martinez, E. Walleser, and J. P. N. Martins. 2021. Effects of $\mathrm{GnRH}$ and $\mathrm{hCG}$ administration during early luteal phase on estrous cycle length, expression of estrus and fertility in lactating dairy cows. Theriogenology 173:23-31. https://doi.org/ 10.1016/j.theriogenology.2021.06.010.

De Rensis, F., F. López-Gatius, I. García-Ispierto, and M. Techakumpu. 2010. Clinical use of human chorionic gonadotropin in dairy cows: an update. Theriogenology 73:1001-1008. https://doi.org/10 .1016/j.theriogenology.2009.11.027. 
Diaz, T., E. J. Schmitt, R. L. de la Sota, M. J. Thatcher, and W. W. Thatcher. 1998. Human chorionic gonadotropin-induced alterations in ovarian follicular dynamics during the estrous cycle of heifers. J. Anim. Sci. 76:1929-1936. https://doi.org/10.2527/ 1998.7671929x.

Domingues, R. R., O. J. Ginther, V. E. Gomez-León, and M. C. Wiltbank. 2020. Up-regulation of endometrial oxytocin receptor is associated with the timing of luteolysis in heifers with two and three follicular waves. Biol. Reprod. 102:316-326. https://doi.org/10 $.1093 /$ biolre/ioz165.

Edmonson, A. J., I. J. Lean, L. D. Weaver, T. Farver, and G. Webster. 1989. A body condition scoring chart for Holstein dairy cows. J. Dairy Sci. 72:68-78. https://doi.org/10.3168/jds.S0022 $-0302(89) 79081-0$

Faul, F., E. Erdfelder, A. Lang, and A. Buchner. 2007. G*Power: A flexible statistical power analysis program for the social, behavioral and biomedical sciences. Behav. Res. Methods 39:175-191. https://doi.org/10.3758/bf03193146.

Flint, A. P., G. E. Lamming, H. J. Stewart, and D. R. Abayasekara. 1994. The role of the endometrial oxytocin receptor in determining the length of the sterile oestrous cycle and ensuring maintenance of luteal function in early pregnancy in ruminants. Philos. Trans. R. Soc. Lond. B Biol. Sci. 344:291-304. https://doi.org/10.1098/ rstb.1994.0067.

Fonseca, F. A., J. H. Britt, B. T. McDaniel, J. C. Wilk, and A. H. Rakes. 1983. Reproductive traits of Holsteins and Jerseys. Effects of age, milk yield, and clinical abnormalities on involution of cervix and uterus, ovulation, estrous cycles, detection of estrus, conception rate, and days open. J. Dairy Sci. 66:1128-1147. https://doi .org/10.3168/jds.S0022-0302(83)81910-9.

Fricke, P. M., L. P. Reynolds, and D. A. Redmer. 1993. Effect of human chorionic gonadotropin administered early in the estrous cycle on ovulation and subsequent luteal function in cows. J. Anim. Sci. 71:1242-1246. https://doi.org/10.2527/1993.7151242x.

Ginther, O. J., H. K. Shrestha, M. J. Fuenzalida, A. K. M. Shahiduzzaman, M. A. Hannan, and M. A. Beg. 2010. Intrapulse temporality between pulses of a metabolite of prostaglandin F $2 \alpha$ and circulating concentrations of progesterone before, during, and after spontaneous luteolysis in heifers. Theriogenology 74:1179-1186. https://doi.org/10.1016/j.theriogenology.2010.05.018.

Ginther, O., L. Silva, R. Araujo, and M. Beg. 2007. Temporal associations among pulses of 13, 14-dihydro-15-keto-PGF2alpha, luteal blood flow, and luteolysis in cattle. Biol. Reprod. 76:506-513. https://doi.org/10.1095/biolreprod.106.057653.

Ginther, O. J., L. Knopf, and J. P. Kastelic. 1989. Temporal associations among ovarian events in cattle during oestrous cycles with two and three follicular waves. Reproduction 87:223-230. https:// doi.org/10.1530/jrf.0.0870223.

Giordano, J. O., M. C. Wiltbank, J. N. Guenther, R. Pawlisch, S. Bas, A. P. Cunha, and P. M. Fricke. 2012. Increased fertility in lactating dairy cows resynchronized with Double-Ovsynch compared with Ovsynch initiated $32 \mathrm{~d}$ after timed artificial insemination. J. Dairy Sci. 95:639-653. https://doi.org/10.3168/jds.2011-4418.

Greco, L. F., J. T. Neves Neto, A. Pedrico, F. S. Lima, R. S. Bisinotto, N. Martinez, E. S. Ribeiro, W. W. Thatcher, C. R. Staples, and J. E. P. Santos. 2018. Effects of altering the ratio of dietary n-6 to n-3 fatty acids on spontaneous luteolysis in lactating dairy cows. J. Dairy Sci. 101:10536-10556. https://doi.org/10.3168/jds.2018 -15065 .

Hawkins, D. E., K. D. Niswender, G. M. Oss, C. L. Moeller, K. G. Odde, H. R. Sawyer, and G. D. Niswender. 1995. An increase in serum lipids increases luteal lipid content and alters the disappearance rate of progesterone in cows. J. Anim. Sci. 73:541-545. https: //doi.org/10.2527/1995.732541x.

Helmer, S. D., and J. H. Britt. 1986. Fertility of dairy cattle treated with human chorionic gonadotropin ( $\mathrm{hCG}$ ) to stimulate progesterone secretion. Theriogenology 26:683-695. https://doi.org/10 .1016/0093-691X(86)90176-7.

Jaiswal, R. S., J. Singh, L. Marshall, and G. P. Adams. 2009. Repeatability of 2 -wave and 3 -wave patterns of ovarian follicular develop- ment during the bovine estrous cycle. Theriogenology 72:81-90. https://doi.org/10.1016/j.theriogenology.2009.02.014.

Lonergan, P. 2011. Influence of progesterone on oocyte quality and embryo development in cows. Theriogenology 76:1594-1601. https: //doi.org/10.1016/j.theriogenology.2011.06.012.

Macmillan, K. L., A. M. Day, V. K. Taufa, M. Gibb, and M. G. Pearce. 1985. Effects of an agonist of gonadotrophin releasing hormone in cattle. I. Hormone concentrations and oestrous cycle length. Anim. Reprod. Sci. 8:203-212. https://doi.org/10.1016/ 0378-4320(85)90025-9.

Martins, J. P. N. 2021. Examples of individual cows for serum concentration of P4, luteal volume, and CL Doppler scores for cows in each treatment. Supplemental figures. http://digital.library.wisc .edu/1793/82420

Martins, J. P. N., and J. R. Pursley. 2016. Fertility programs for lactating dairy cows, their physiological basis, and the factors that are critical for their success. Anim. Reprod. 13:283-289. https:// doi.org/10.21451/1984-3143-AR881.

Martins, J. P. N., R. K. Policelli, L. M. Neuder, W. Raphael, and J. R. Pursley. 2011. Effects of cloprostenol sodium at final prostaglandin F2 $\alpha$ of Ovsynch on complete luteolysis and pregnancy per artificial insemination in lactating dairy cows. J. Dairy Sci 94:2815-2824. https://doi.org/10.3168/jds.2010-3652.

McCracken, J. A., E. E. Custer, and J. C. Lamsa. 1999. Luteolysis: A neuroendocrine-mediated event. Physiol. Rev. 79:263-323. https:/ /doi.org/10.1152/physrev.1999.79.2.263.

Miller, W. R., R. Williams, G. W. Pipes, and C. W. Turner. 1963. Conjugation, distribution, and biological half-life (t 1/2) of radioactive progesterone in plasma and red cells of bovine blood J. Dairy Sci. 46:1402-1404. https://doi.org/10.3168/jds.S0022 -0302(63)89289-9.

Nascimento, A. B., R. W. Bender, A. H. Souza, H. Ayres, R. R. Araujo, J. N. Guenther, R. Sartori, and M. C. Wiltbank. 2013. Effect of treatment with human chorionic gonadotropin on day 5 after timed artificial insemination on fertility of lactating dairy cows. J. Dairy Sci. 96:2873-2882. https://doi.org/10.3168/jds.2012-5895.

Nascimento, A. B., A. H. Souza, A. Keskin, R. Sartori, and M. C. Wiltbank. 2014. Lack of complete regression of the Day 5 corpus luteum after one or two doses of PGF2 $\alpha$ in nonlactating Holstein cows. Theriogenology 81:389-395. https://doi.org/10.1016/j .theriogenology.2013.10.009.

Niles, A. M., H. P. Fricke, P. D. Carvalho, M. C. Wiltbank, L. L. Hernandez, and P. M. Fricke. 2019. Effect of treatment with human chorionic gonadotropin 7 days after artificial insemination or at the time of embryo transfer on reproductive outcomes in nulliparous Holstein heifers. J. Dairy Sci. 102:2593-2606. https://doi.org/ 10.3168 /jds.2018-15588.

NRC. 1971. A Guide to Environmental Research on Animals. National Academies.

Palhão, M. P., A. C. Ribeiro, A. B. Martins, C. R. B. Guimarães, R. D. Alvarez, M. F. Seber, C. A. C. Fernandes, J. P. Neves, and J. H. M. Viana. 2020. Early resynchronization of non-pregnant beef cows based in corpus luteum blood flow evaluation 21 days after timed-AI. Theriogenology 146:26-30. https://doi.org/10.1016/j .theriogenology.2020.01.064.

Pugliesi, G., R. G. Rezende, J. C. B. d. Silva, E. Lopes, T. K. Nishimura, P. S. Baruselli, E. H. Madureira, and M. Binelli. 2017. Use of Doppler ultrasonography in timed-AI and ET programs in cattle. Rev. Bras. Reprod. Anim. 41:140-150.

Pursley, J. R., M. O. Mee, and M. C. Wiltbank. 1995. Synchronization of ovulation in dairy cows using PGF2 $\alpha$ and GnRH. Theriogenology 44:915-923. https://doi.org/10.1016/0093-691X(95)00279-H.

Pursley, J. R., and J. P. N. Martins. 2011. Impact of circulating concentrations of progesterone and antral age of the ovulatory follicle on fertility of high-producing lactating dairy cows. Reprod. Fertil. Dev. 24:267-271. https://doi.org/10.1071/RD11917.

Rizos, D., S. Scully, A. Kelly, A. D. Ealy, R. Moros, P. Duffy, A. Al Naib, N. Forde, and P. Lonergan. 2012. Effects of human chorionic gonadotrophin administration on day 5 after oestrus on corpus luteum characteristics, circulating progesterone and conceptus elon- 
gation in cattle. Reprod. Fertil. Dev. 24:472-481. https://doi.org/ 10.1071/RD11139.

Robinson, R. S., G. E. Mann, G. E. Lamming, and D. C. Wathes. 2001. Expression of oxytocin, oestrogen and progesterone receptors in uterine biopsy samples throughout the oestrous cycle and early pregnancy in cows. Reproduction 122:965-979. https://doi .org/10.1530/rep.0.1220965.

Sangsritavong, S., D. K. Combs, R. Sartori, L. E. Armentano, and M. C. Wiltbank. 2002. High feed intake increases liver blood flow and metabolism of progesterone and estradiol-17beta in dairy cattle. J. Dairy Sci. 85:2831-2842. https://doi.org/10.3168/jds.S0022 -0302(02)74370-1.

Santos, J. E., W. W. Thatcher, L. Pool, and M. W. Overton. 2001. Effect of human chorionic gonadotropin on luteal function and reproductive performance of high-producing lactating Holstein dairy cows. J. Anim. Sci. 79:2881-2894. https://doi.org/10.2527/2001 .79112881x.

Sartori, R., J. M. Haughian, R. D. Shaver, G. J. Rosa, and M. C. Wiltbank. 2004. Comparison of ovarian function and circulating steroids in estrous cycles of Holstein heifers and lactating cows. J. Dairy Sci. 87:905-920. https://doi.org/10.3168/jds.S0022 -0302(04)73235-X.

Savio, J. D., M. P. Boland, and J. F. Roche. 1990. Development of dominant follicles and length of ovarian cycles in post-partum dairy cows. J. Reprod. Fertil. 88:581-591. https://doi.org/10 $.1530 /$ jrf.0.0880581.

Schmitt, E. J., C. M. Barros, P. A. Fields, M. J. Fields, T. Diaz, J. M. Kluge, and W. W. Thatcher. 1996a. A cellular and endocrine characterization of the original and induced corpus luteum after administration of a gonadotropin-releasing hormone agonist or human chorionic gonadotropin on day five of the estrous cycle. J. Anim. Sci. 74:1915-1929. https://doi.org/10.2527/1996.7481915x.

Schmitt, E. J., T. Diaz, C. M. Barros, R. L. de la Sota, M. Drost, E. W. Fredriksson, C. R. Staples, R. Thorner, and W. W. Thatcher. 1996b. Differential response of the luteal phase and fertility in cattle following ovulation of the first-wave follicle with human chorionic gonadotropin or an agonist of gonadotropin-releasing hormone. J. Anim. Sci. 74:1074-1083. https://doi.org/10.2527/1996 $.7451074 x$.

Sianangama, P. C., and R. Rajamahendran. 1992. Effect of human chorionic gonadotropin administered at specific times following breeding on milk progesterone and pregnancy in cows. Theriogenology 38:85-96. https://doi.org/10.1016/0093-691X(92)90220 $-\mathrm{L}$.

Sianangama, P. C., and R. Rajamahendran. 1996. Effect of hCG administration on day 7 of the estrous cycle on follicular dynamics and cycle length in cows. Theriogenology 45:583-592. https://doi .org/10.1016/0093-691X(95)00405-W.

Thatcher, W. W. 2017. A 100-year review: Historical development of female reproductive physiology in dairy cattle. J. Dairy Sci. 100:10272-10291. https://doi.org/10.3168/jds.2017-13399.

Tsai, S. J., and M. C. Wiltbank. 1998. Prostaglandin F2 $\alpha$ regulates distinct physiological changes in early and mid-cycle bovine corpora lutea. Biol. Reprod. 58:346-352. https://doi.org/10.1095/ biolreprod58.2.346.

Vasconcelos, J. L., R. W. Silcox, G. J. Rosa, J. R. Pursley, and M. C. Wiltbank. 1999. Synchronization rate, size of the ovulatory follicle, and pregnancy rate after synchronization of ovulation beginning on different days of the estrous cycle in lactating dairy cows. Theriogenology 52:1067-1078. https://doi.org/10.1016/S0093 $-691 X(99) 00195-8$.

Vasconcelos, J. L. M., O. G. Sá Filho, P. L. T. Justolin, P. Morelli, F. L. Aragon, M. B. Veras, and S. Soriano. 2011. Effects of postbreeding gonadotropin treatments on conception rates of lactating dairy cows subjected to timed artificial insemination or embryo transfer in a tropical environment. J. Dairy Sci. 94:223-234. https://doi .org/10.3168/jds.2010-3462.

Wiltbank, M. C., G. M. Baez, F. Cochrane, R. V. Barletta, C. R. Trayford, and R. T. Joseph. 2015. Effect of a second treatment with prostaglandin F2 $\alpha$ during the Ovsynch protocol on luteolysis and pregnancy in dairy cows. J. Dairy Sci. 98:8644-8654. https:// doi.org/10.3168/jds.2015-9353.

Wiltbank, M. C., and J. R. Pursley. 2014. The cow as an induced ovulator: Timed AI after synchronization of ovulation. Theriogenology 81:170-185. https://doi.org/10.1016/j.theriogenology.2013.09.017.

Zolini, A. M., W. G. Ortiz, E. Estrada-Cortes, M. S. Ortega, S. Dikmen, F. Sosa, J. O. Giordano, and P. J. Hansen. 2019. Interactions of human chorionic gonadotropin with genotype and parity on fertility responses of lactating dairy cows. J. Dairy Sci. 102:846-856. https://doi.org/10.3168/jds.2018-15358. 